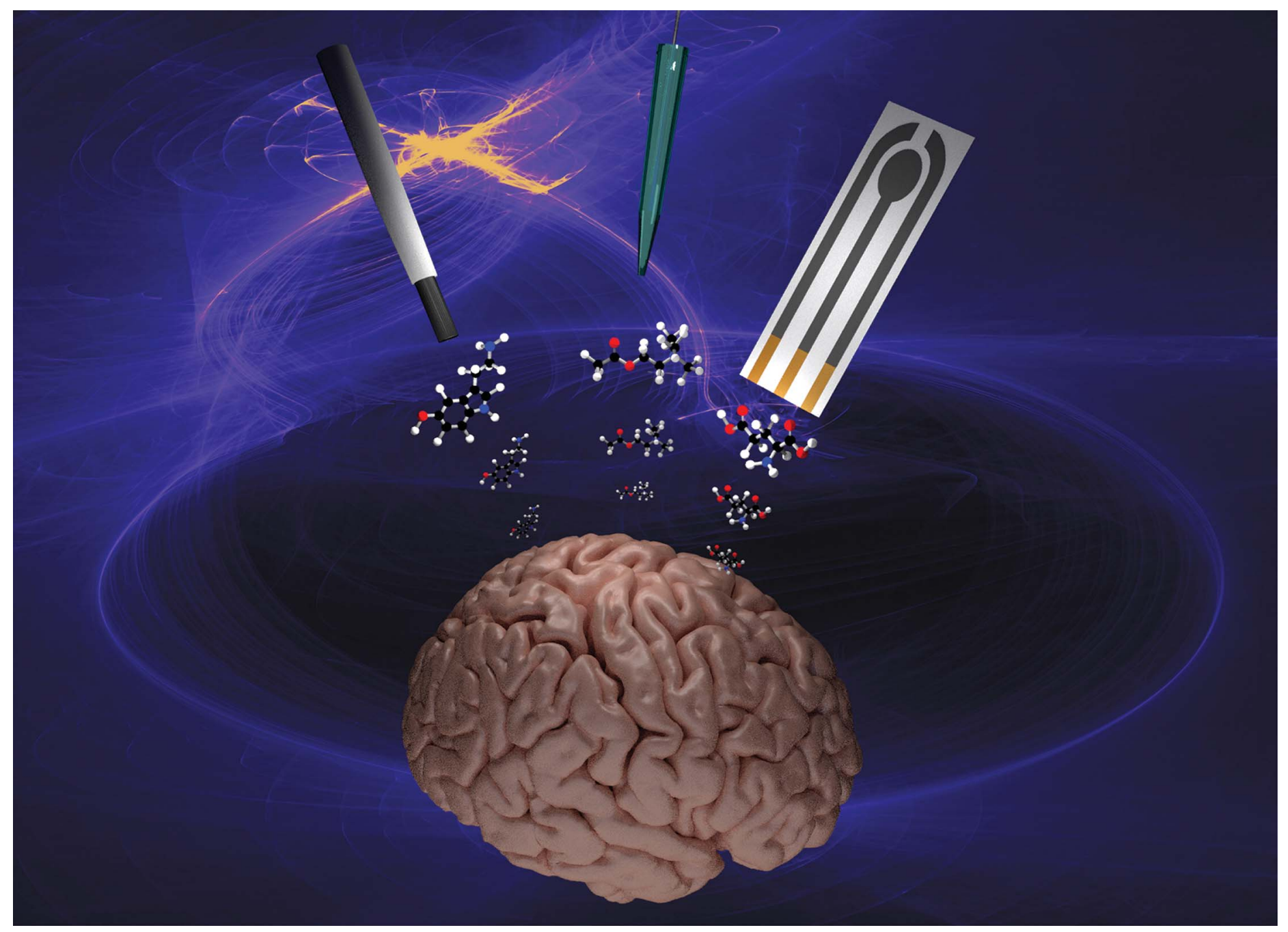

Showcasing research from Professor Hashemi's laboratory, Department of Chemistry \& Biochemistry, University of South Carolina, Columbia, SC, USA. Shane Berger, Jordan Holmes, and Anderson Winkler are acknowledged for their contribution to the cover image.

Frontiers in electrochemical sensors for neurotransmitter detection: towards measuring neurotransmitters as chemical diagnostics for brain disorders

Unlike disorders in the periphery, it is extremely challenging to chemically diagnose disorders of the brain. There is thus great interest in designing and optimizing tools for direct detection of chemical biomarkers implicated in neurological disorders to improve diagnosis and treatment. This critical review highlights significant technical advances and in vivo studies from the last five years that will facilitate the development of diagnostic tools for brain disorders. Although none of these devices are currently used for diagnostic purposes, these cutting-edge technologies are promising more sensitive, selective, faster, and less invasive measurements.

\section{As featured in:}

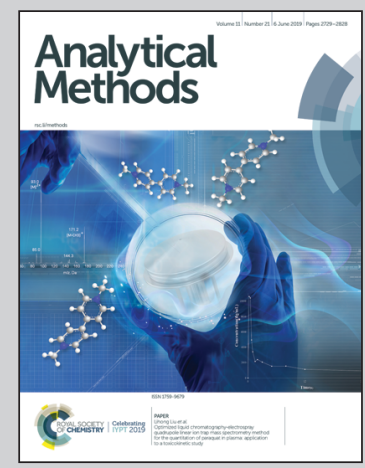

See Parastoo Hashemi et al., Anal. Methods, 2019, 11, 2738.

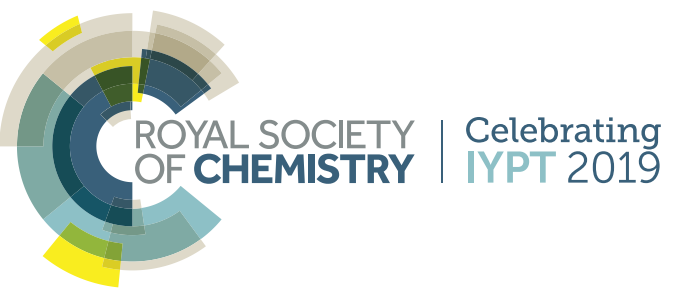


Check for updates

Cite this: Anal. Methods, 2019, 11, 2738

\title{
Frontiers in electrochemical sensors for neurotransmitter detection: towards measuring neurotransmitters as chemical diagnostics for brain disorders
}

\begin{abstract}
Yangguang Ou, (D) Anna Marie Buchanan, Colby E. Witt and Parastoo Hashemi (D) *
It is extremely challenging to chemically diagnose disorders of the brain. There is hence great interest in designing and optimizing tools for direct detection of chemical biomarkers implicated in neurological disorders to improve diagnosis and treatment. Tools that are capable of monitoring brain chemicals, neurotransmitters in particular, need to be biocompatible, perform with high spatiotemporal resolution, and ensure high selectivity and sensitivity. Recent advances in electrochemical methods are addressing these criteria; the resulting devices demonstrate great promise for in vivo neurotransmitter detection. None of these devices are currently used for diagnostic purposes, however these cutting-edge technologies are promising more sensitive, selective, faster, and less invasive measurements. Via this review we highlight significant technical advances and in vivo studies, performed in the last 5 years, that

we believe will facilitate the development of diagnostic tools for brain disorders.
\end{abstract}

Received 7th January 2019

Accepted 15th March 2019

DOI: $10.1039 / c 9 a y 00055 k$

rsc.li/methods

\section{Introduction}

Unlike illnesses of the body, such as diabetes or cancer, disorders of the brain, such as depression, do not have defined diagnostic protocols with quantifiable chemical biomarkers. The inability to definitively diagnose mental disorders means that it is also difficult to effectively treat them: antidepressants, for example, are largely ineffective for the majority of patients. ${ }^{1}$ There is, thus, enormous interest by us and others to identify chemical biomarkers of brain disorders so that illnesses of the brain can be better diagnosed and treated.

Biomarkers of brain disorders have been difficult to identify for two primary reasons. First, the blood brain barrier maintains strict and different chemical climates between the brain and the periphery, such that peripheral blood does not reflect the brain's chemical microenvironment. Secondly, it is extremely difficult to probe the chemistry, namely neurotransmission, of an intact brain (in vivo). Analysis of neurotransmission necessitates micro or nano level spatial resolution, which is particularly challenging given the intricate nature of brain tissue. Additionally, the brain is chemically harsh and complex and neurotransmission is dynamic (occurring on the sub-seconds).

In the last decade, microengineering is the cutting-edge method to produce devices that are small, fast, and chemically reactive enough to meet some of the challenges of

Department of Chemistry and Biochemistry, University of South Carolina, Columbia, SC, USA. E-mail: parry.hashemi@gmail.com measuring neurotransmitters in vivo. There are three main categories of in vivo neurotransmitter detection devices; fluorescence probes, sampling (e.g. microdialysis), and electrochemistry. There are distinct pros and cons for each class of method, however electrochemical methods are particularly suited to in vivo sampling because they are able to perform direct chemical measurements in deep brain tissue without the need for artificial tags or sample treatment/analysis.

Via this review, we highlight the most recent advancements in the development of electrochemical microdevices over the last five years in the detection and quantitation of various important neurotransmitters to brain disorders, including glutamate (Glu), acetylcholine (ACh), dopamine (DA) and serotonin (5-HT). We focus mostly on amperometric biosensors and voltammetry in this review. While most of the literatures cited are primarily performed in vivo, we choose to highlight some in vitro and ex vivo work that further the progress of the field as well as display promising potential for future in vivo experiments.

While few of the reviewed methods have been implemented in humans and none have been used for diagnostics, we believe these devices show promise towards rapidly enabling chemical biomarker identification in the brain. Such a transition will revolutionize diagnosis and treatment of disorders of the brain.

\section{Monitoring neurotransmission}

Neurotransmitters are small molecules that relay chemical messages between brain cells via a process called neurotransmission (Fig. 1). As such, the intricacies of neurochemical 


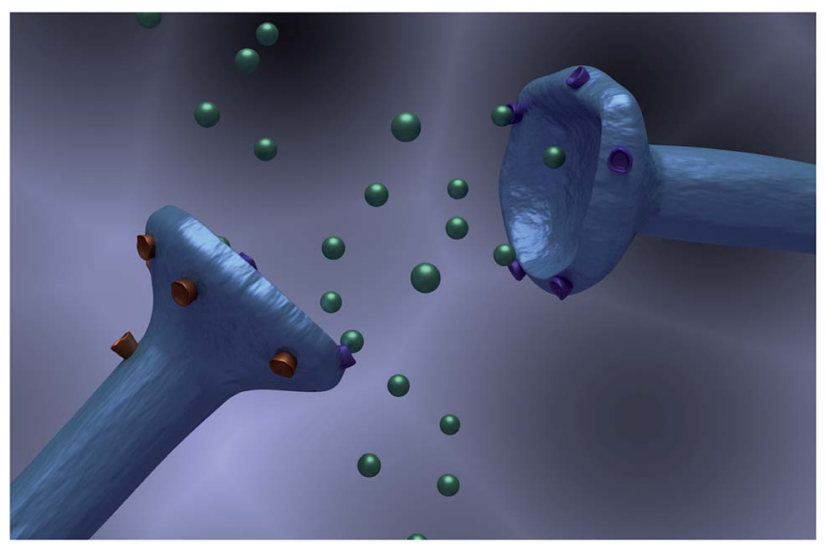

Fig. 1 Illustration of a synapse. Presynaptic cell is on the left and postsynaptic cell is on the right. Green spheres represent neurotransmitters. Autoreceptors are shown in orange and postsynaptic receptors in purple.

signaling are of particular interest in the diagnosis and treatment of psychological disorders. Neurotransmission is rapid (milliseconds) and occurs over several general steps. First, the transmitter is synthesized via presynaptic processes. Release of neurotransmitter from the presynaptic cell into the synaptic space is via $\mathrm{Ca}^{2+}$ initiated exocytosis. Following release, the transmitter binds to receptors on the postsynaptic cell or to autoreceptors on the presynaptic cell. Finally, the signal is terminated through reuptake back into the presynaptic cell by a transporter, followed by intracellular catabolism or via direct extracellular catabolism.

Classical neurotransmission is mediated by excitatory neurotransmitters such as Glu and ACh and the inhibitory neurotransmitter gamma-aminobutyric acid (GABA), which, because of their potency and cytotoxicity, are confined to the synaptic space. Neuromodulators, such as DA, 5-HT, norepinephrine, and histamine (HA), are types of neurotransmitters that signal through "volume transmission." Unlike Glu, ACh and GABA, these molecules diffuse outside of the synapse exerting influence over many cells over a large spatial area.

This review explores electrochemical neurotransmitter measurements in the context of neurotransmission. Two categories of electrochemical techniques are of particular interest: voltammetry and biosensors.

\section{Voltammetry}

A variety of voltammetric techniques are utilized to directly detect electroactive molecules. These techniques are characterized by the application of a potential waveform to an electrode and the measurement of the resulting current. ${ }^{2}$ Because of the rapid time frame of neurotransmission, fast-scan cyclic voltammetry (FSCV) is of particular interest throughout this review. In FSCV, a waveform with a fast scan rate is applied to a microelectrode, at high frequency (typically $10 \mathrm{~Hz}$ ), affording measurements with millisecond timescale. ${ }^{3}$ This method is coupled to carbon fiber microelectrodes (CFMs) of 5-7 $\mu \mathrm{m}$ in diameter. This small probe size promotes high spatial resolution and negligible tissue damage. ${ }^{4}$ Fig. 2 shows the two electron oxidation/reduction of DA at a CFM that results in a stereotypical DA fast scan cyclic voltammogram. There are some drawbacks to FSCV measurements. Firstly, a limited number of neurotransmitters have electroactivity that lends itself to FSCV detection. This issue has made detection of neurotransmitters such as Glu, GABA, and ACh difficult. Selectivity is also a concern; the monoamines DA, 5-HT, and norepinephrine oxidize at similar potentials and are colocalized in many of the same brain regions. In many cases, waveform optimization and pharmacological manipulation are implemented to differentiate between the molecules and to reduce

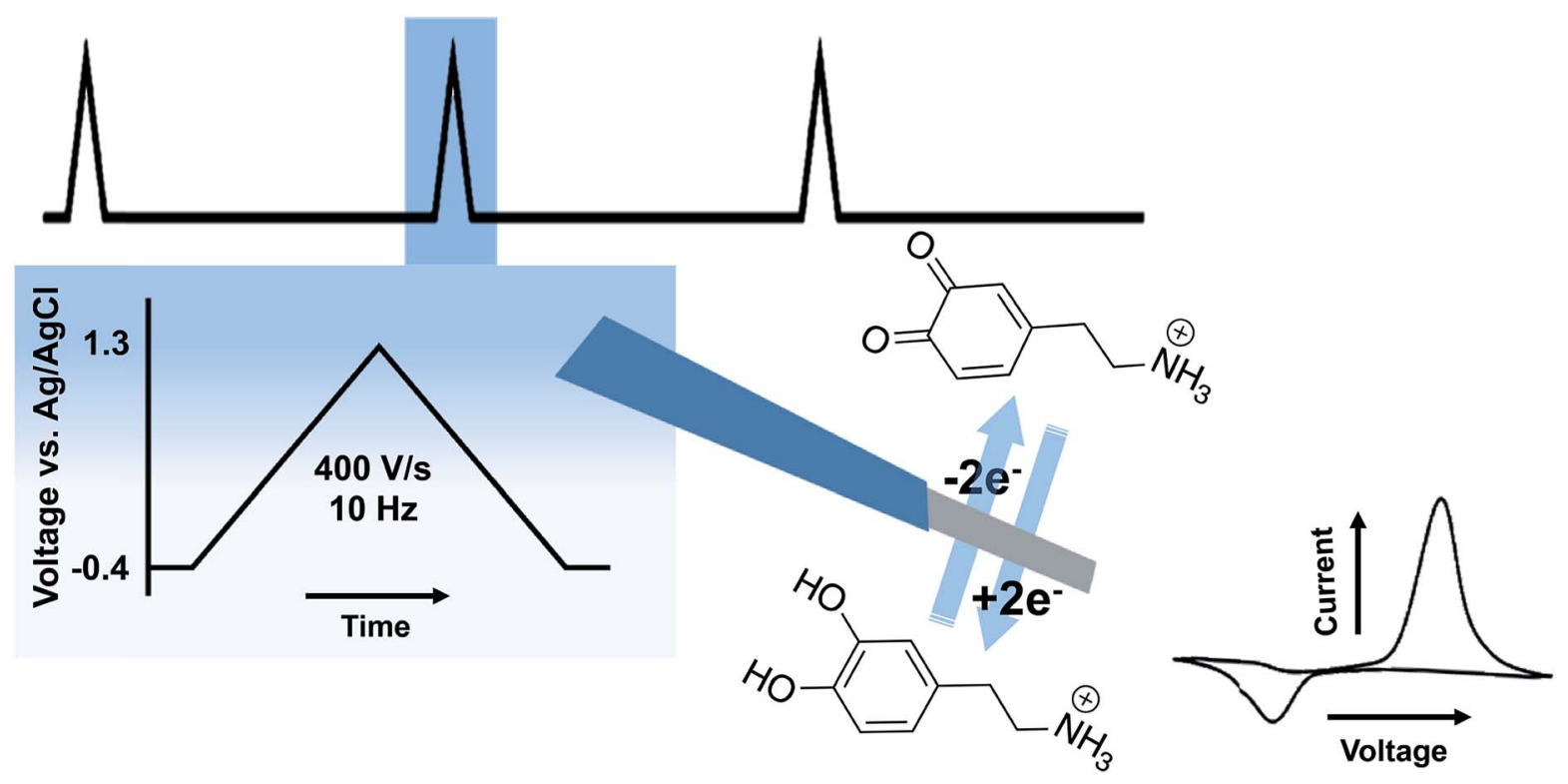

Fig. 2 Schematic of FSCV at CFMs. The top shows the waveform. The blue box shows the parameters of the waveform. In the middle is an illustration of a CFM performing a two-electron oxidation/reduction of DA with a representative cyclic voltammogram to the right. 
signals due to other interferents. This review will explore advancements made in FSCV to address existing limitations and to provide additional insight into the complexities of neurotransmission.

\section{Biosensors}

When the analyte of interest is not easily electroactive, biosensors can be applied. Biosensors are devices that create an electrical signal in response to the analyte via a biocatalyst such as an enzyme, antibody or DNA. ${ }^{5}$ Electrochemical biosensors commonly involve immobilization of an enzyme at an electrode surface. This enzyme is selective for an analyte of interest. As an example, the enzyme Glu oxidase oxidizes Glu and reduces $\mathrm{O}_{2}$ to $\mathrm{H}_{2} \mathrm{O}_{2}$. While Glu is not readily electroactive, $\mathrm{H}_{2} \mathrm{O}_{2}$ can be easily oxidized. Thus amperometry (current measured at constant potential) can quantify Glu via $\mathrm{H}_{2} \mathrm{O}_{2}$ oxidation. A generalized biosensor scheme is shown in Fig. 3. The major advantages of biosensors are the high selectivity afforded by the biological molecule and electrochemical detection of chemicals that are not electroactive within the potential window of traditional electrode materials. However, the use of enzymes produces many challenges. Sufficient enzyme loading for high sensitivity, membranes and immobilizing matrices often necessitates large probes, which is undesirable for measurement in delicate brain tissue. $^{6}$ Additionally, immobilization methods can cause

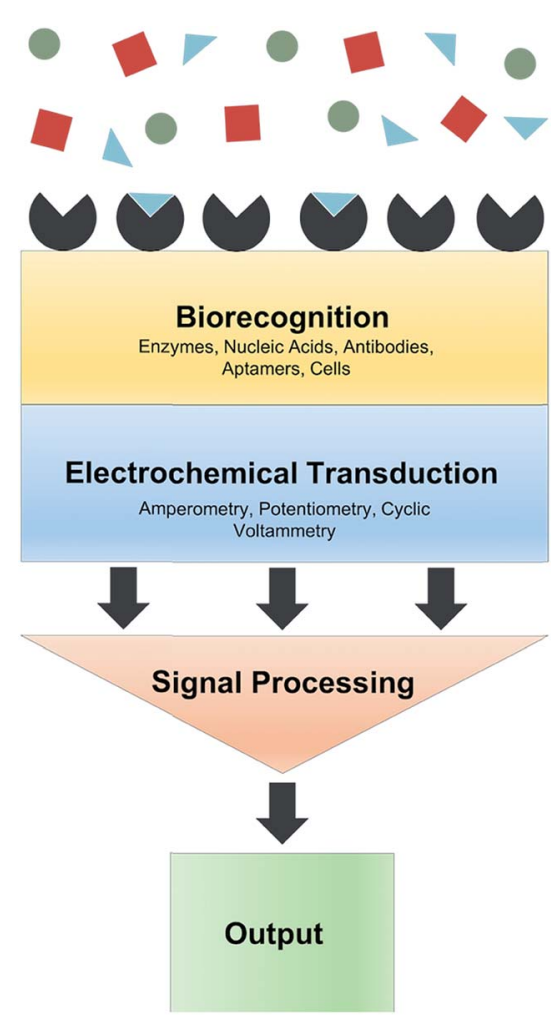

Fig. 3 Schematic of an electrochemical biosensor. A typical biosensor consists of a biorecognition element selective for the molecule of interest (blue triangles) within a given matrix (red squares and green circles), a transducer that converts the input into a measurable signal, and signal processing and output components. conformational changes in the enzyme, lowering catalytic activity, stability and shelf-life. ${ }^{7}$ Efforts to overcome these obstacles for in vivo measurements are highlighted throughout this review.

\section{Glutamate (Glu)}

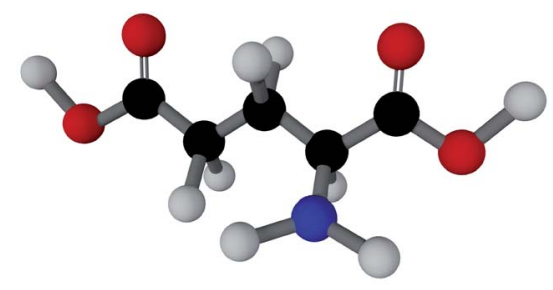

Structure 1. Glu Molecule

\section{Introduction}

Glu is one of the most ubiquitous neurotransmitters ${ }^{8}$ that binds to NMDA ( $N$-methyl-D-aspartate), kainate, AMPA ( $\alpha$-amino-3hydroxy-5-methyl-4-isoxazole-propionic acid), and metabotropic receptors. ${ }^{9}$ Because Glu is highly excitatory, this messenger can exert excitotoxic effects and is thus rapidly uptaken via excitatory amino acid transporters located on the plasma membrane of astrocytes and neurons. ${ }^{\mathbf{1 0 , 1 1}}$ This high level of regulation presents difficulties for analytical Glu measurements since Glu cannot readily escape the synapse like the neuromodulators described later in this review. Additionally, Glu is not electroactive within the potential window of conventional electrode materials. These two phenomena present unique challenges for Glu detection.

The extraction and purification of Glu oxidase ${ }^{\mathbf{1 2}}$ enabled development of selective Glu biosensors, the frontline electrochemical Glu detection devices. Working electrodes in these sensors can be made from carbon fiber ${ }^{13}$ or diamond ${ }^{\mathbf{1 4}}$ but are most commonly composed of platinum..$^{15}$ Substrate materials for creating sensing platforms, including arrays, are primarily silicon or ceramic. ${ }^{\mathbf{1 6}}$ Strategies for immobilizing the enzyme onto the electrode surface include direct adsorption, covalent binding, cross-linking, ${ }^{17}$ and entrapment in polymers (reviewed in Scouten et al. ${ }^{18}$ Freire et al., ${ }^{19}$ Putzbach et al. ${ }^{20}$ and Hughes et $a .^{21}$ ). Immobilization of enzymes in polymeric membranes, especially electrochemically deposited polymers, ${ }^{22-34}$ gained increasing attention due to a variety of factors, ${ }^{23}$ particularly the ability to prevent interfering molecules from reaching the electrode. Self-referencing is another strategy used to reduce signals from other electrochemically active species. ${ }^{34-36}$ This approach involves a second electrode that mimics the working electrode in all respects but does not contain enzyme. This ensures that signals from any non-selective binding of species to the electrode surface can be subtracted out.

One major limitation for biosensors is poor electron transfer between the enzyme and the electrode due to the tunneling 
distance between the enzyme's electron transfer center and the electrode. To improve signal transduction, various functional nanomaterials ${ }^{37-40}$ and redox mediators ${ }^{41-43}$ were incorporated into the electrode design. ${ }^{44}$ Using these general strategies, Glu biosensors were utilized to investigate the dynamics of this messenger in the brain.

\section{Glutamate in sleep/wake and reward}

Electrochemical measurement of Glu could have implications for diagnosis of sleeping and addictive disorders. Glu biosensors have been used in the mouse prefrontal cortex (PFC) to investigate Glu's roles in the sleep/wake cycle. For example, Naylor et al. found that extracellular Glu levels correspond well to the sleep/wake cycle. Glu levels were higher during the awake state and lower during the sleep state with transients during periods of REM sleep. ${ }^{45}$ Further work found chronically high levels of extracellular Glu in the same brain region in animal models with Rett syndrome, which is marked by severe sleep deprivation-like symptoms. ${ }^{46}$

Glu biosensors have also been utilized to investigate reward circuitry. An initial dose of nicotine induced rapid, transient Glu release in the ventral tegmental area and the nucleus accumbens, regions that make up the mesolimbic system, a neural system highly implicated in reward. ${ }^{47}$ Cocaine administration induced similar phasic Glu release in the nucleus accumbens shell. ${ }^{48}$ Repeated doses of nicotine increased tonic Glu that correlated with drug-induced hyperlocomotion. ${ }^{47}$ Repeated doses of cocaine had similar effects in the dorsal striatum $^{49}$ and an interesting biphasic release profile in the nucleus accumbens shell. ${ }^{48}$ Wassum et al. measured rapid Glu transients prior to lever pressing in rodent models of rewardseeking behavior. ${ }^{33,50}$ These studies generally implied a role for Glu in cue-evoked reward behaviors; however, a 2015 study showed that Glu release from selective activation of glial cells inhibited reinstatement of cocaine seeking behavior. ${ }^{51}$ Thus, Glu's roles in reward seeking are clearly complicated and warrant more investigations.

Technological advances over the last five years include using novel materials to enhance sensitivity, stability, response time, and cost effectiveness of these sensors. There has also been a push to address the oxygen-sensitivity of glutamate sensors by replacing glutamate oxidase with other enzymes. Additionally, it is clear that other analytes and chemicals work in tandem with Glu. Thus, there is a need for multi-analyte measurements and integrated devices. We review novel technical advancements below.

\section{Novel technical advancements for glutamate biosensors}

Materials. Novel materials have been used in recent years to enhance the intrinsic properties of Glu biosensors. The first generation of Glu biosensors utilize molecular oxygen as the electron acceptor to form $\mathrm{H}_{2} \mathrm{O}_{2}$, which is electrochemically detected. Accurate measurements of Glu in oxygen-poor environments, such as hypoxia, thus pose a problem. To tackle this, researchers turned to cerium oxide, a co-immobilization material that can trap and release oxygen from its crystalline structure. ${ }^{52}$ Shi et al. developed second generation biosensors using chitosan as a directional immobilization matrix for both Glu oxidase and redox mediators. ${ }^{53}$ These matrices are particularly useful for small electrode areas that cannot be dropcoated or screen-printed. The group found that immobilization via chitosan provided faster response times than sensors cross-linked to the electrode via the traditional glutaraldehyde linker. ${ }^{54}$

Weltin et al. used a flexible polyimide-based substrate as the wafer for sensor design, instead of the more rigid silicon or ceramic alternatives. The authors pointed out that soft materials cause less tissue damage and demonstrated the utility of this sensor by measuring Glu in vivo. ${ }^{55}$ In a follow-up study, the same group created multiparametric devices via hybrid thinfilm and laminate technology using polyimide substrates. ${ }^{\mathbf{5 6}}$ The device included sensors for Glu, lactate, oxygen, and glucose detection simultaneously.

The polymers used for biosensors are also important. Clay et al. recently developed a mathematical model for optimizing conditions of electroenzymatic sensors for optimal Glu detection. The model accurately predicted the sensitivity for Glu sensors made by immobilizing Glu oxidase with various polymeric films. Simulations demonstrated that a significant amount $(>95 \%)$ of $\mathrm{H}_{2} \mathrm{O}_{2}$ generated in the thick enzyme layers tend to diffuse back to the sample solution, suggesting that biosensors made with thinner films $(1-3 \mu \mathrm{m})$ were optimal. In fact, the simulations showed that these films would yield several-fold improvement in both sensitivity and response time. The model was for a specifically constructed device; however, it can be used as a blueprint for optimizing other enzyme-based biosensors. ${ }^{57}$

Other notable examples of novel materials include hybrid carbon materials by Sainio et al., who demonstrated that electrodes made with tetrahedral amorphous carbon nanofibers had a larger potential window than conventional electrode materials and could measure Glu without enzymes. ${ }^{58}$ Nasr et al. developed a borosilicate micropipette-based biosensor covered with self-organized nanostructures, whose large surface area increased sensitivity for Glu detection in stem cell-derived brain organoids. ${ }^{59}$

Enzyme alternatives. Oxygen is an important consideration in glutamate sensing. First-generation sensors require oxygen to function while second-generation sensors use artificial redox mediators, which oxygen competes with. Thus, a limitation of first-generation glutamate sensors is oxygen deprivation while a limitation of second-generation sensors is oxygen interference (reviewed in Jamal et al. ${ }^{60}$ ). One way to overcome these issues is to replace the glutamate oxidase enzyme in these sensors with other enzymes. The most common approach has been to replace glutamate oxidase with glutamate dehydrogenase. ${ }^{61-63}$ $\mathrm{Wu}$ et al. recently discovered that ferredoxin-dependent glutamate synthase also has bioelectrocatalyst properties and can be tuned to either catalyze glutamate synthesis or glutamate oxidation by careful selection of redox mediators. ${ }^{64}$ This discovery is notable for a new generation of glutamate biosensor design because (1) it overcomes the oxygen sensitivity seen in previous generations and (2) since the redox-active region is 
close to the surface of the enzyme, it provides a method that allows for direct electron transfer between the enzyme and the electrode surface.

Multi-modal and integrated glutamate measurements. An ongoing challenge for electrochemical sensor design is to measure both electroactive and non-electroactive neurotransmitters with the same device. Moore et al. used a commercially available Glu biosensor, incorporating ascorbic acid (AA) oxidase (to inactivate this interfering species) and measured DA and Glu at constant potential. Although there is less selectivity when using fixed potential instead of FSCV, the authors argued that it is a worthy trade-off to be able to detect multiple neurotransmitters at the same device. The group used this technique to measure phasic and tonic changes in Glu and DA during sexual behavior of hamsters. ${ }^{65}$ In a similar approach, Massicotte et al. created a novel complementary metal-oxidesemiconductor amperometric system for multi-electrode measurements of DA and Glu. ${ }^{66}$ Like Moore et al., this group recognized the reduced selectivity with constant potential detection of DA and proposed the use of adaptable carbon nanotube-based coatings for reducing interferences. Ferreira et al. created microbiosensors for ascorbate and Glu, and then combined the two in an array for simultaneous measurements in vivo ${ }^{67}$ Fig. 4 shows the CFM (left) modified with Nafion ${ }^{\mathrm{TM}}$ and single-walled carbon nanotube (with an LOD of $0.7 \mu \mathrm{M}$ ) for ascorbate sensing and ceramic microelectrode arrays (right) for Glu sensing. The middle is a micropipette for delivering local stimulus solution.

Electrophysiology is one of the most commonly used techniques in neuroscience and monitors neuronal activity as

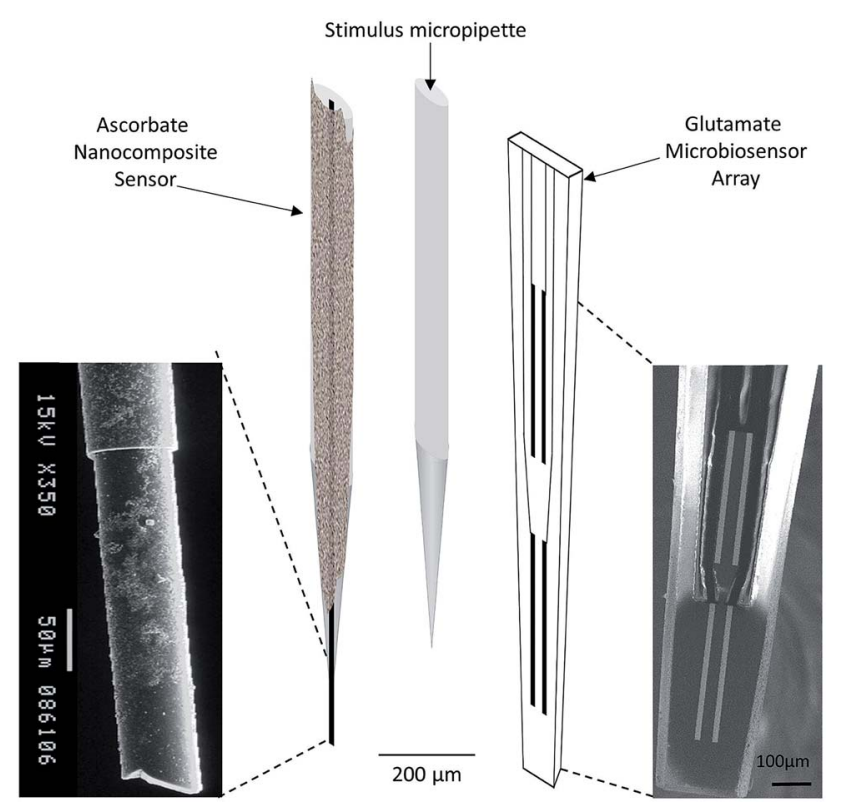

Fig. 4 Schematic representation of array composed by ascorbate nanocomposite microsensor (left), Glu microbiosensor (right) and the micropipette (center) for local application of solutions in the extracellular space of the rat hippocampus. Reproduced from Ferreira et al. with permission. ${ }^{67}$ a function of a DC shift. Wei et al. developed silicon-based implantable microelectrode arrays with a microelectromechanical system technology for simultaneous in vivo Glu and electrophysiological recordings in the striatum of anesthetized rats. ${ }^{68}$ In a similar approach, Fan et al. created a 16-channel silicon-based array based on microelectromechanical system technology. Twelve of the 16 electrodes were modified with platinum black, a "spongy" electrode material with excellent catalytic properties, for electrophysiological recordings of neural firing. The remaining 4 electrodes were modified with Glu oxidase for Glu measurements in vivo. This microelectrode array was implanted into the cortex and hippocampus of mice and Glu concentrations were found to be higher in the hippocampus despite slower firing rates of neurons. ${ }^{69}$

\section{Acetylcholine (ACh)}

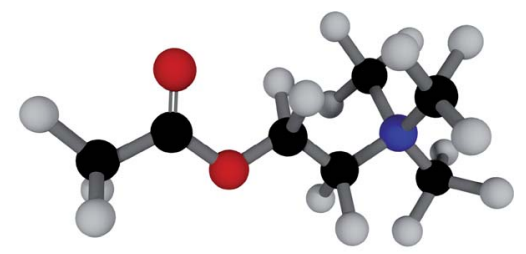

Structure 2. ACh Molecule

\section{Introduction}

ACh binds to two main classes of receptors: nicotinic and muscarinic. Ionotropic nicotinic receptors are present in relatively low abundance in the brain, with the majority of cholinergic receptors being metabotropic muscarinic receptors. ${ }^{70}$ Furthermore, ACh is unique among neurotransmitters because the ACh's signal is terminated exclusively through extracellular degradation of the molecule via acetylcholinesterase in the synapse that rapidly breaks down this molecule into choline and acetate. Choline is then taken up by the presynaptic cell. Because ACh is not electroactive within the potential window of most biocompatible materials, efforts to measure the molecule have mostly focused on the exploitation of ACh metabolism. Electrochemical enzyme-based sensors for ACh have been developed using either choline oxidase or a combination of acetylcholinesterase and choline oxidase. Enzymes are immobilized on the electrode surface via different approaches and the catalytically generated $\mathrm{H}_{2} \mathrm{O}_{2}$ is detected amperometrically. ${ }^{71}$

Duel-enzyme biosensors measured the sum of choline and ACh signals via choline oxidase and acetylcholinesterase enzymes. ${ }^{72}$ To refine this approach, self-referencing sensors, with separate sites for $\mathrm{ACh} /$ choline and choline detection, allowed interfering signals to be subtracted out and independently quantify choline and ACh signals in vivo. ${ }^{73,74}$

In terms of unraveling ACh's role in the brain using biosensors, Parikh et al. were the first to use a simpler single sensor approach of measuring choline in awake, behaving 
animals. The electrode was modified with choline oxidase, assuming choline is a direct index of ACh. ${ }^{75}$ The keynote studies from this group laid the foundation for investigating ACh's roles in attention and memory, the most recent of the findings of which are reviewed below.

\section{Acetylcholine's role in attention and memory}

ACh measurements with electrochemical devices may prove critical in diagnosis of attention and memory disorders, including neurodegenerative diseases such Alzheimer's disease. ACh biosensors have time resolution on the order of seconds or subseconds and have been able to capture transient changes in ACh concentration. ${ }^{75,76}$ For example, cholinergic transients associated with attentional performance in cue detection behavioral tasks were measured in the PFC of rodents. ${ }^{77}$ In this experiment, animals responded to a visual light cue by pressing an assigned lever for a food reward. The evidence presented in the paper suggested that choline plays a role in switching from monitoring a response to acting upon it. ${ }^{77}$ In a follow up study, optogenetic stimulation of cholinergic transients increased the probability of correctly acting upon a response. ${ }^{78}$ The same group used combined approaches (choline measurements, electrophysiology and pharmacology) to show that cholinergic transients were concomitant with increased neuronal synchronicity across several neuronal firing frequency bands and the emergence of thetagamma coupling (a neurophysiologic process underlying working memory).$^{79}$ Thus the group revealed the important role that ACh may play in linking attention to memory. ${ }^{79}$ Synchronized release of ACh has also been observed across brain regions; Teles-Grilo Ruivo et al. used a dual-enzyme biosensor to measure coordinated ACh release in the PFC and hippocampus of freely moving mice performing a working memory task. ${ }^{80}$

While there have been exciting advancements in the detection of choline and $\mathrm{ACh}$, there are existing difficulties in in vivo measurements. Technological advances in the last five years attempted to address some of these, including probe size, stability, temporal resolution, and toxicity. These are addressed in the following section. Some of the papers described are designed for environmental studies but the technical innovations, we believe, can be applied to future in vivo sensor design.

\section{Frontiers in acetylcholine biosensing}

Acetylcholine measurements on a nano level. A novel nanopipette-based electrode addressed size limitations associated with $\mathrm{ACh}$ measurements. ${ }^{81}$ Photograph and scanning electron micrograph of this small probe can be seen in Fig. $5 \mathrm{~A}$ and B, respectively. This electrode utilized assisted ion transfer at nanopipettes combined with cyclic voltammetry (Fig. 5C) and amperometry. The probe was filled with an organic solvent and implanted into an aqueous environment, which is immiscible with the fill solution in the probe. The pipette supported the interface between two immiscible electrolyte solutions (ITIES) and measured ion transfer across a liquid-liquid interface rather than a redox process, allowing for traditionally nonelectroactive molecules to be quantitatively measured. The electrodes ranged in size from $\sim 14$ to $70 \mathrm{~nm}$ in diameter,

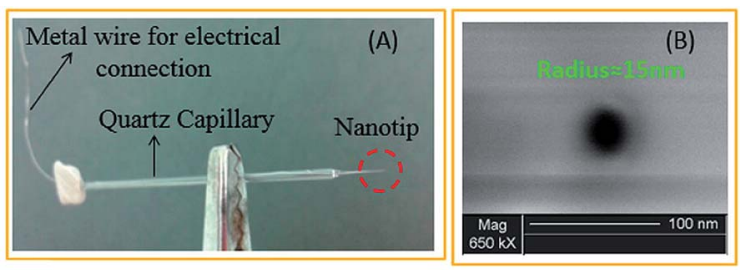

(C)

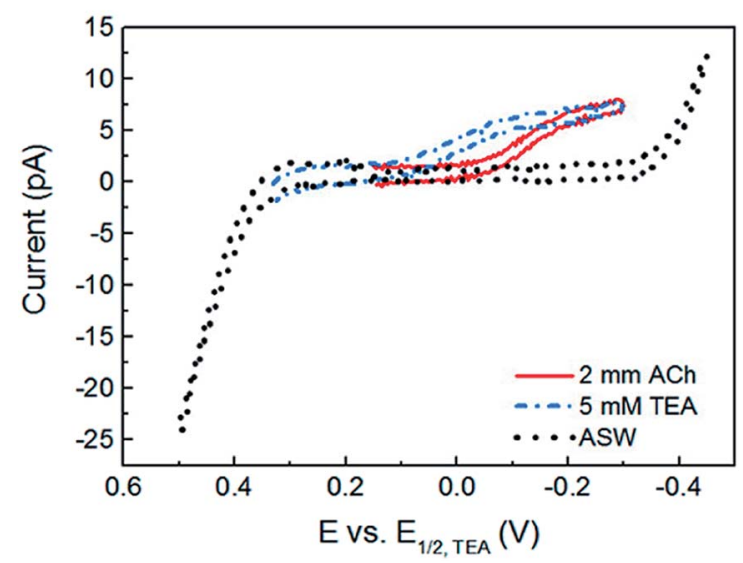

Fig. 5 (A) Photograph and (B) scanning electron micrograph of a nanopipette prepared by a laser-pulled capillary. (C) Cyclic voltammogram of $2 \mathrm{mM}$ acetylcholine (ACh), tetraethylammonium (TEA), and artificial seawater (ASW). TEA was used as an internal standard and ASW was the solvent (background signal). Adapted with permission from Colombo et al. ${ }^{81}$

significantly smaller than the traditional microelectrode. These nanoITIES electrodes were used to measure ACh release from both the soma and a single synapse of Aplysia californica cells. $^{82,83}$ A concentration of $2.7 \pm 1.0 \mu \mathrm{M}$ released ACh was measured from a single soma, with a releasable vesicle density of $25 \pm 2$ vesicles per $\mu \mathrm{m}^{2}$.

Stability. An ongoing issue with ACh biosensors is poor stability and longevity due to loss of enzyme activity. Baker et al. utilized stabilizing agents, including methyl methacrylate, cellulose acetate, bovine serum albumin, glutaraldehyde, and polyethyleneimine that permitted stable, chronic in vivo implantation of choline sensors up to 14 days. ${ }^{84}$ Kanik et al. used the conjugated polymer poly(4-(2,5-di(thiophen-2-yl-)-1Hpyrrol-1-yl)benzamine) to create both mechanically and chemically stable biosensors without the need for redox mediators. ${ }^{85}$ Utilizing carbon nanospheres that create unique 3D structures for high enzyme entrapment, Cai et al. created an ACh sensor that maintained $80 \%$ of its response after 20 days. ${ }^{86}$ A different approach was to entrap acetylcholinesterase within a hybrid silica mesoporous membrane, which, due to its large interconnected pores, enabled high enzyme loading and minimized denaturing: ${ }^{87}$ This sensor maintained $90 \%$ of its response after 60 days of storage. Even longer sensor lifetimes, up to 4 months, have been reported. ${ }^{88}$

Temporal resolution. Santos et al. created a choline biosensor with a temporal resolution of $1.4 \mathrm{~s} .{ }^{89}$ This sensor was composed of two $50 \mu \mathrm{m}$ diameter Pt/Ir disks constructed side-by-side with choline oxidase immobilized onto the electrode surfaces with 
chitosan as the matrix and $p$-benzoquinone as the linker. This sensor provided high spatiotemporal resolution for spontaneous choline measurements in sub-regions of the hippocampus. ${ }^{89}$ Mousavi et al. created a potentiometric ionophore-doped ionselective electrode which did not require enzyme modification. ${ }^{\mathbf{9 0}}$ The potentiometric method measured the partition of the cationic 5-HT molecule between the sample and a hydrophobic ionselective membrane doped with calixarene, a hydrophobic molecule whose binding cavity mimics that of acetylcholinesterase. This sensor had a response time of $<1$ second and was used successfully in rat brain homogenates. Keighron et al. modified carbon fiber microdisk electrodes with spatially discrete nanoparticles, onto which acetylcholinesterase and choline oxidase were deposited..$^{\mathbf{1}}$ The enzyme layer was near monolayer thickness, allowing for rapid (millisecond) response time, the fastest reported for biosensing tools. This technique was used to measure exocytotic ACh release from artificial secretory cells.

Green acetylcholine detection. A fast-growing interest for sensor design is sustainability. For biosensors this means renewable enzyme interfaces for reusable sensors. Zhang et al. used the layer-by-layer self-assembly technique to create a renewable ACh biosensor.92 The enzyme interfaces were renewed by treatment with $\mathrm{NaOH}$ and fresh layers of multiwalled carbon nanotubes with polyethylenediamine and acetylcholinesterase. Researchers are also increasingly interested in the use of safe materials. The immobilization and interference rejection polymer poly-phenylenediamine has been suggested to be carcinogenic. ${ }^{93}$ Phenol-derived films ${ }^{93}$ as well as nanocomposites, made of gold-coated iron oxide nanoparticles with chitosan, ${ }^{\mathbf{9 4}}$ show promise for safe materials. Using these materials, Chauhan et al. created an iron oxide nanoparticle poly(3,4-ethylenedioxythiophene)-reduced graphene oxide nanocomposite modified fluorine doped tin oxide biosensor for rapid (4 s), sensitive (4 $\mathrm{nM})$ ACh detection in serum. ${ }^{95}$

\section{Dopamine (DA)}

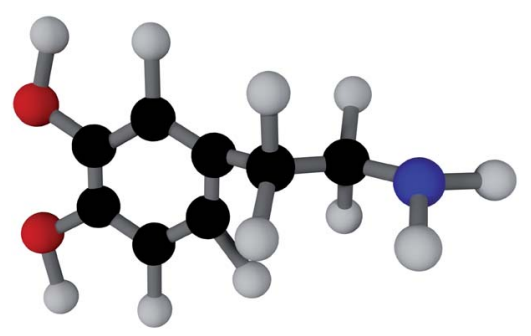

Structure 3. DA Molecule

\section{Introduction}

DA is a neuromodulator and is released, by the fusion of presynaptic vesicles to the cell membrane, in the extracellular space. DA exerts its effects, via volume transmission, to modulate the function of other neurotransmitters. DA has five major receptor subtypes $\left(D_{1}-D_{5}\right)$ and is regulated via autoreceptors, heteroreceptors and transporters. ${ }^{\mathbf{9 6}}$

CFMs were discovered to be useful sensors for in vivo DA measurements due to their biological compatibility ${ }^{97,98}$ and renewable surfaces. ${ }^{\mathbf{9 9 , 1 0 0}}$ Early days of DA measurements were plagued by interferences, particularly significant contribution from AA, which is present in much higher quantities in the brain than DA. ${ }^{\mathbf{1 0 1}}$ However, it was demonstrated that holding the potential at $-0.4 \mathrm{~V}$ preconcentrates the positively charged DA ion, ${ }^{102}$ and increasing scan rate allows DA oxidation (whose electron transfer kinetics are faster than that of $\mathrm{AA}$ ) to overshadow AA oxidation. ${ }^{103}$ New instrumentation was created to simplify measurements and data analysis. ${ }^{104}$ Dopamine was measured with FSCV as evoked with electrical stimulation, ${ }^{\mathbf{1 0 5}}$ and Rebec et al. were the first to observe DA transients during behavior. ${ }^{106}$ We know precipitously more about the functions of DA in the brain than other transmitters because of this breakthrough technique, typified by the work of Mark Wightman over the last four decades. These works have enabled routine study of DA by many members of the community.

\section{Dopamine in cognition and reward}

Electrochemical devices that measure DA have wide reaching diagnostic potential, for example in addictive and cognitive disorders and neurodegenerative diseases such Parkinson's disease (characterized by loss of DA neurons). DA FSCV technology described above culminated, among other seminal findings, in establishing DA's major roles in reward and cognition. ${ }^{107-115}$ These findings spearheaded an explosion of studies to understand these behaviors in the context of the dopaminergic system. In particular, it was found that the reward-related behaviors described above are controlled by the mesolimbic DA circuits, which are in turn modulated by endogenous factors such as hormones. Naef et al. showed that insulin administration reduced DA release in the nucleus accumbens as well as attenuated cocaine-induced DA spikes and locomotor hyperactivity. ${ }^{\mathbf{1 1 6}}$ The hormone estradiol was found to increase the DA mediated potency of cocaine, ${ }^{117}$ a finding that could explain the sexual dimorphism in addiction vulnerability. Another interesting finding has been that the stress hormone corticosterone potentiates DA signaling via inhibition of the organic cation transporter (OCT) 3, which may explain stress-induced drug relapse behavior. ${ }^{118}$

Other notable investigations involving DA FSCV include measuring this modulator in humans playing a reward based investment game during surgery for deep brain stimulation for Parkinson's disease ${ }^{\mathbf{1 1 9}}$ and after administration of chemotherapy drugs in a zebra fish model of chemo brain. ${ }^{\mathbf{1 2 0 - 1 2 2}}$ An additional recent direction is deciphering DA/5-HT modulation in the context of alcohol consumption ${ }^{123}$ and response to neutral stimuli in animal models. ${ }^{\mathbf{1 2 4}}$

Recent technical advances in the last five years, including improvement of calibration, measurement of ambient DA levels, monitoring multiple analytes simultaneously, chronic measurements, and integrating in vivo voltammetry with other platforms are highlighted below. 


\section{Technical advancements}

Calibration. Calibration is an ongoing issue for FSCV. CFMs are typically fabricated in-house; thus calibration of each electrode is necessary to ensure quality. There is ongoing discussion in the field as to whether to employ pre- or post-experiment calibrations. In either case, in vitro calibrations do not reflect the in vivo performance of the electrode. This is because calibrations are performed in buffer solutions that cannot replicate the in vivo environment. Additionally, in vivo proteins adsorb to and foul electrodes, resulting in loss of sensitivity. Furthermore, in most experiments, the tip of the electrode must be exposed to a high enough potential to lesion the surrounding tissue for location determination, a process that renders post-calibrations impossible. ${ }^{\mathbf{1 2 5 , 1 2 6}}$ To overcome these issues, various mathematical tactics have been employed.

Via a total-background-current strategy, Roberts et al. created a quadratic model relating sensitivity to background current and switching potential. ${ }^{\mathbf{2 5}}$ The group showed that the model was a good predictor of in vivo sensitivity. An alternative approach is to use principal component regression, which captured information from the shape of the background current to better provide estimates of sensitivity. ${ }^{\mathbf{1 2 6}}$ Meunier et al. built upon this principal component regression strategy by modeling impedance changes due to electrode fouling with simple circuits, thereby improving the accuracy of predicted background current. ${ }^{127}$

Chronic dopamine measurements. The majority of in vivo FSCV studies span $4-8 \mathrm{~h}$. There is great interest to make measurements at a CFM in the same position over an extended period of time to understand neurochemical changes during behavior and/or chronic pharmacological manipulations. Chronic measurements have been a topic of interest for some time, for a discussion of chronic FSCV methods before 2013, we refer the reader to a review by Wightman and colleagues. ${ }^{128}$

One of the chief issues with chronic measurements is the loss of electrode material over time. ${ }^{\mathbf{1 0 0}}$ Nimbalkar et al. designed and fabricated a new class of homogeneous glassy carbon neural probes with no adhesion or conducting metal layers, thereby enhancing the lifetime of the probe for long periods of electrical stimulation (for deep brain stimulation, for example). ${ }^{129}$ Interestingly, the same probe materials were capable of stimulating in addition to performing neurochemical measurements. ${ }^{129}$

Another hindrance to using traditional FSCV carbon fiber probes for chronic measurements is the size of the probe shaft, which induced inflammatory responses. While the probe tip was on the order of 5-7 $\mu \mathrm{m}$, the probe shaft can be as large as $100 \mu \mathrm{m}$. Inflammatory responses can foul the electrode surface, reducing the lifetime of the electrode. Schwerdt et al. recently replaced the glass shaft of the conventional CFMs with parylene, which provides robustness in a thinly deposited layer surrounding the carbon fiber, resulting in $<10 \mu \mathrm{m}$ size probe shafts. These probes were fabricated into arrays and implanted in rodent, ${ }^{\mathbf{1 3 0}}$ and non-human primate ${ }^{\mathbf{1 3 1}}$ brains for successful multi-channel simultaneous DA measurements for over 100 days in vivo.
Ambient dopamine levels. FSCV is background-subtracted because of a large double layer charging current that results from application of fast scan rates. Because of this, a change must be evoked in the system, usually via electrical stimulation. Background subtraction has thus prevented measurement of tonic or ambient, steady state levels of neurotransmitters in vivo. In 2012, the Wightman group utilized pharmacology to report tonic DA levels at around $20 \mathrm{nM} .^{132}$ The following text highlights recent approaches to measuring ambient DA levels.

Atcherley et al. modified FSCV and coined a novel method, fast-scan controlled-adsorption voltammetry (FSCAV). ${ }^{\mathbf{1 3 3}}$ Fig. 6 shows that DA FSCAV takes place over three distinct steps: (1) the triangle waveform $\left(-0.4\right.$ to $1.3 \mathrm{~V}$, scan rate $\left.=1200 \mathrm{~V} \mathrm{~s}^{-1}\right)$ was applied at a high frequency of $100 \mathrm{~Hz}$ to minimize adsorption of DA to the electrode surface (A, purple region); (2) a fixed potential $(-0.4 \mathrm{~V})$ was applied to the electrode system, allowing for DA to adsorb to the electrode surface for a controlled amount of time (A, blue region); and (3) the waveform was then reapplied at the same frequency to measure the adsorbed DA (A, green region). Fig. 6B shows a representative color plot, from which the first current $v s$. time curve with the representative DA peak (Fig. 6C) is used to quantify the total charge underneath the peak. Total charge was then plotted against concentration (Fig. 6D) to generate a calibration curve.

Atcherley et al. reported a tonic concentration of $90 \pm 9 \mathrm{nM}$ of DA in the nucleus accumbens core of an anesthetized mouse with a limit of detection of $3.4 \pm 0.8 \mathrm{nM}$ and a temporal resolution of 30 s. $^{134,135}$ FSCAV was recently coupled to FSCV to concurrently measure both stimulated release and tonic DA in brain slices. ${ }^{135}$ In an alternate strategy, Oh et al. changed the waveform for FSCV into a "Mexican hat" waveform and introduced a dual-background subtraction protocol to measure tonic DA. ${ }^{\mathbf{1 3 6}}$ They termed this new method charge balancing multiple waveform FSCV. In a follow up study, the group utilized multiple cyclic square wave voltammetry for measuring tonic DA, which, like FSCAV, also utilized a holding potential period to control DA adsorption onto the carbon fiber. In this method, they modeled the fast capacitive current decays using a simple exponential decay equation and subtracted it out from the raw signal. ${ }^{137}$

Other approaches used mathematics to address the issue of the large background current. Johnson and Wightman optimized an experimental protocol in order to simplify background current to those that can be mathematically explained and then used a convolution-based method to predict and remove the resistive-capacitive component of the CFM background current. ${ }^{138}$

Simultaneous measures of other analytes with dopamine. Waveform and enzyme modifications have enabled simultaneous detection of DA with other analytes. The typical DA FSCV waveform has a positive potential limit of $+1.3 \mathrm{~V} \cdot{ }^{\mathbf{1 3 9}}$ By scanning more positive than this $(+1.4 \mathrm{~V})$ Spanos et al. were able to capture an oxidation peak for $\mathrm{H}_{2} \mathrm{O}_{2}$ in addition to DA. ${ }^{\mathbf{1 4 0}}$ The group found that $\mathrm{H}_{2} \mathrm{O}_{2}$ levels attenuated both phasic and tonic levels of DA in vivo in the rat dorsal striatum. The same group reported that holding the potential of the traditional DA at 
A

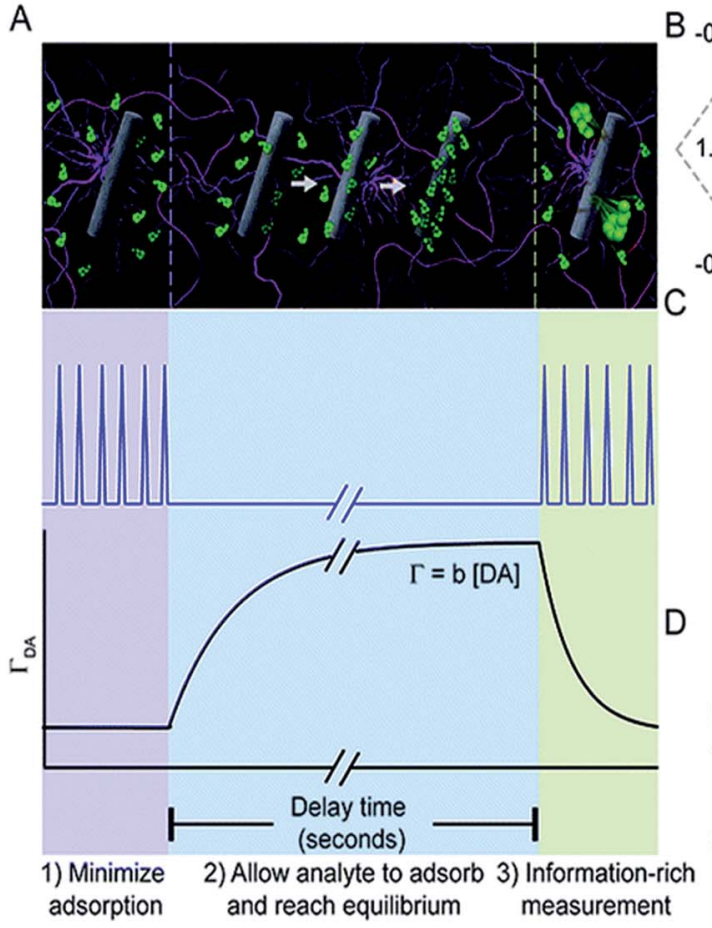

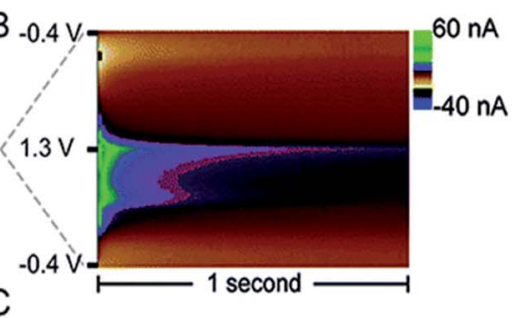
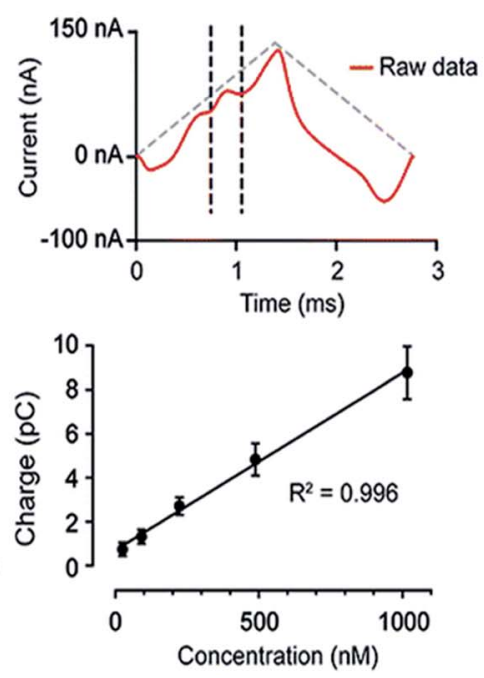

Fig. 6 FSCAV was carried out in 3 steps (A): (1) the waveform was applied every 10 milliseconds which minimizes DA adsorption to the electrode. (2) The potential was held at $-0.4 \mathrm{~V}$ for 10 seconds to allow DA to adsorb to the electrode and reach equilibrium. (3) The waveform was reapplied, and the adsorbed DA was measured. Surface-accumulated DA ( $\Gamma D A)$ is proportional to the tonic concentration [DA] by the strength of adsorption. (B) Resultant color plot from step 3, with voltage on the ordinate, time on the abscissa, and current displayed using false colors. (C) Representative current trace (red) taken 10 milliseconds after the beginning of step 3. The vertical dashed lines show the bounds for integration to quantify adsorbed DA. The grey-dashed triangles illustrate the voltage waveform applied. (D) A calibration plot obtained by FSCAV post implantation $\left(R^{2}=0.996\right.$, slope $=0.0078 \pm 0.0002 \mathrm{pC} \mathrm{nM}^{-1}(n=7$ electrodes $\left.)\right)$, which when accounting for electrode area and equivalents transferred, corresponds to $b=0.0037 \pm 0.0002 \mathrm{~cm}$. Reproduced with permission from Atcherley et al. ${ }^{133}$

$-0.2 \mathrm{~V}$ (instead of $-0.4 \mathrm{~V}$ ), allowed for simultaneous detection of glucose (via $\mathrm{H}_{2} \mathrm{O}_{2}$ generated from a layer of glucose oxidase on the CFM) and DA. ${ }^{141}$ They found that stimulated release of DA in vivo was followed by an increase in glucose to meet the increased energy demanded by the stimulation. The Cans group constructed an amperometric biosensor by immobilizing an ultra-thin layer of glucose oxidase onto a Au-nanoparticlecovered CFM that permitted the simultaneous monitoring of glucose and DA with millisecond temporal resolution for both analytes. ${ }^{142}$

Other surface modifications have enabled detection of other analytes with DA. Cincotto et al. modified glassy carbon electrodes with a hybrid material consisting of mesoporous silica nanoparticles, graphene, and silver nanoparticles for simultaneous electrocatalytic reduction measurements of DA and epinephrine. ${ }^{143}$ Stephen and colleagues modified glassy carbon electrodes with a poly(o-methoxyaniline)-gold nanocomposite, which reduced overpotentials and separated overlapping peaks for simultaneous folic acid and DA detection. ${ }^{144} \mathrm{Si}$ et al. used pyrrole and $o$-phenylenediamine monomers to form molecularly imprinted polymers for simultaneous detection of DA, norepinephrine, and epinephrine using differential pulse voltammetry. ${ }^{145}$
Other notable multimodal technology include work done by Lee $e t$ al., who improved upon a previous generation of their multi-modal device, called WINCS (wireless instantaneous neurotransmitter concentration sensing), by making a multichannel version called WINCS Harmoni. ${ }^{146}$ Fig. 7 shows (A) a photograph of the WINCS Harmoni device, (B) schematic of the functional components, (C) the analog-to-digital converter, and (D) typical calibration curves from each of the four recording channels. The beauty of this device lies in four primary aspects: (1) the wireless component reduces instrumentation clutter, (2) the multi-channel allows for simultaneous FSCV DA recordings in up to four channels, (3) the design allows for concurrent recordings of both striatal DA and 5-HT in the substantia nigra ( $\mathrm{SNr}$ ), and (4) a closed loop paradigm that gives the user the ability to adjust deep brain stimulation parameters based on real-time monitoring of neurotransmitter release in vivo. The authors successfully demonstrated the versatility of this device in swine, rodent, and non-human primate models. ${ }^{147}$

Dopamine measurements integrated with electrophysiology. An integrated measurement platform known as DANA (DA and Neural Activity) was developed by Parent et al. to obtain near simultaneous electrophysiological and DA FSCV measurements. ${ }^{149}$ 


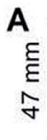

$A$
है
ริ
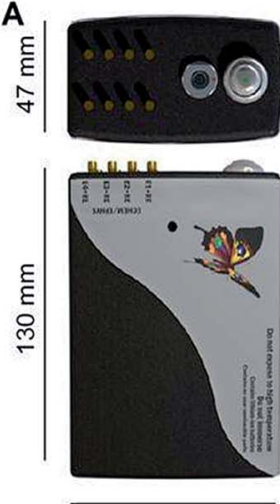

$84 \mathrm{~mm}$

C

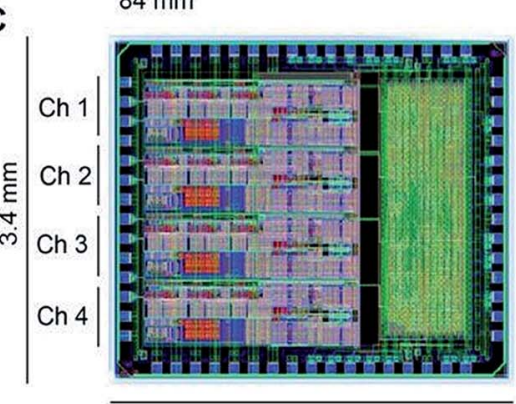

$4 \mathrm{~mm}$
B
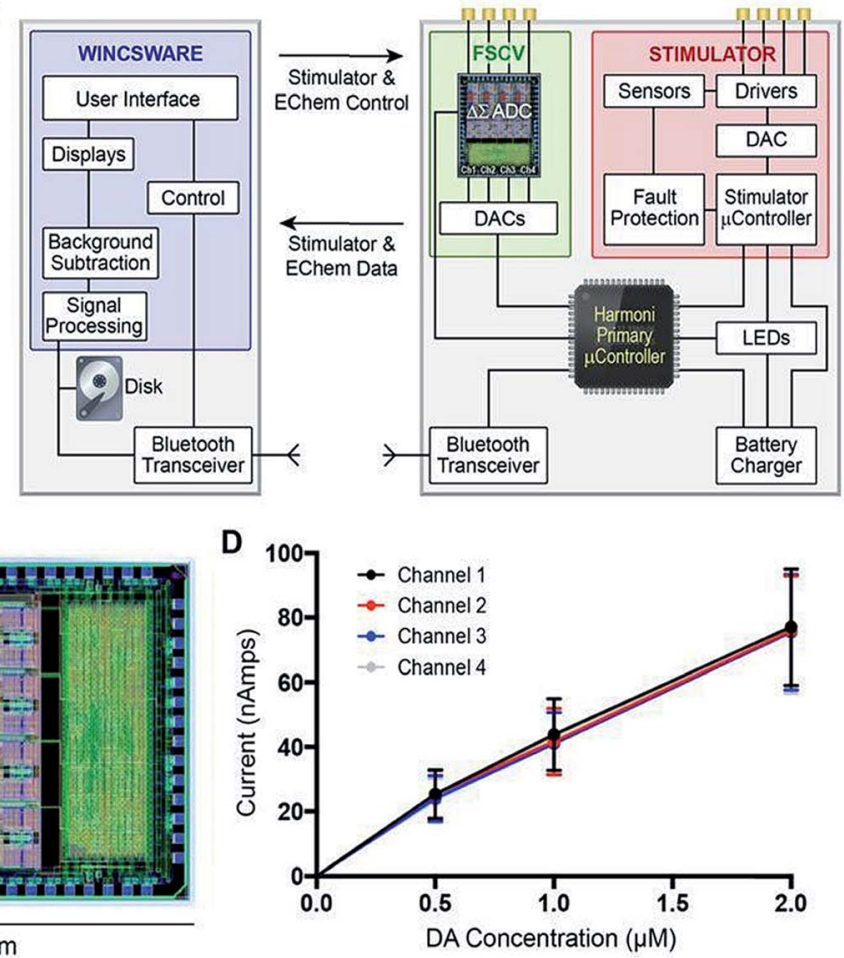

Fig. 7 (A) Photograph of the WINCS Harmoni device; (B) schematic diagram showing the functional components in WINCS Harmoni, including the neurochemical sensing and stimulation boards, charging components, bluetooth transceiver, primary microcontroller, and control software in the base station; (C) image and dimensions of the WINCS Harmoni delta sigma $(\Delta \Sigma)$ analog-to-digital converter (ADC) that enables four channels of simultaneous neurochemical recordings; (D) typical calibration curves for each of the four neurochemical recording channels in WINCS Harmoni showing a linear relationship between DA oxidation current and DA concentration. Reproduced with permission from Lee et $a l^{148}$

Single-unit and DA measurements were collected in awake and freely moving rats to demonstrate the potential of DANA to connect behavior to physiology and neurochemistry. ${ }^{149}$ Work from the Kassegne group created a DA and neural activity platform using four-channel glassy carbon flexible electrode array in four distinct brain regions. ${ }^{150}$

Spreading depolarization (SD) is a pathological process characterized by propagating waves of cell firing. SD waves can be diagnostic events for cell death in penumbral tissues but because of the non-specific firing associated with SD waves, multi-modal analyses are necessary for investigation of the phenomenon. Hobbs et al. created an integrated multimodal device that monitors oxygen levels (an indicator of cerebral blood flow and energy consumption) concurrently with DA and single unit recordings. ${ }^{151}$ The benefit of this microdevice is that it eliminated the need for multiple sensors, which are cumbersome but also cause significantly tissue damage. The group observed significant oxygen and DA fluctuations during spreading depolarization events.

Other notable publications include a multi-functional microelectrode array that contained nearly 60000 electrodes and over 2000 electrophysiology channels for stimulation, FSCV, and impedance measurements in rat cortical neurons and cerebellar slices. ${ }^{152}$

\section{Serotonin $(5-\mathrm{HT})$}

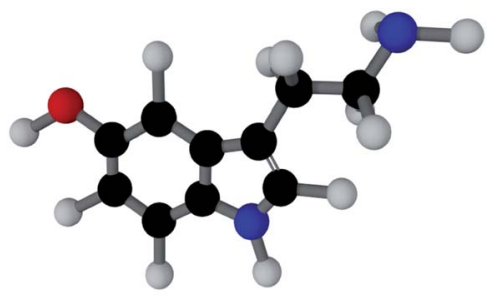

Structure 4. 5-HT Molecule

\section{Introduction}

5-HT is a neuromodulator with a complex receptor profile. On the postsynaptic cell, 5-HT receptors include 2 inhibitory and 11 excitatory G protein-coupled receptors (GCPRs), and a ligandgated ion channel $\left(5-\mathrm{HT}_{3}\right)$. 5 - $\mathrm{HT}$ signals are terminated via multiple mechanisms:

(a) Reuptake into presynaptic neuron and glia by 5 -HT transporters (SERTs), known as Uptake 1. 
(b) Reuptake into other neuron types by monoamine transporters (DATs, norepinephrine transporters (NETs) or organic cation transporters (OCTs)), known as Uptake 2.

(c) Presynaptic autoreceptor binding.

(d) Intracellular metabolism by monoamine oxidases. ${ }^{153,154}$

5-HT is electroactive like DA, however, it has been greatly challenging to apply the tools successful for DA analysis to 5-HT measurements. For many decades, electrochemical 5-HT measurements were limited to ex vivo preparations such as cerebral spinal fluid ${ }^{155}$ or tissue slice preparations. ${ }^{156}$ Direct 5 -HT detection in vivo was not achieved as early as DA detection because 5-HT oxidation products rapidly polymerize and foul the electrode surface. In 1995, Jackson et al. set the groundwork for detecting exogenous 5-HT in vivo using FSCV with a novel waveform $\left(+0.2\right.$ to +1.0 to -0.1 to $\left.+0.2 \mathrm{~V}, 1000 \mathrm{~V} \mathrm{~s}^{-1}\right)$, that dramatically decreased electrode fouling. ${ }^{157}$ They utilized this waveform in a 'mock' in vivo experiment, modeled after an experiment performed by Stamford et al., where dopaminergic neurons were induced to release 5-HT via inhibition of DA synthesis and preloading with 5-hydroxytryptophan (5-HTP), the 5-HT precursor. ${ }^{158}$ In 2009, Hashemi et al. were the first to describe endogenous 5HT measurements in mammalian models. ${ }^{139}$ They described the primary difficulty of in vivo measurements as 5-HT's highly concentrated, electroactive metabolite, 5-hydroxyindoleacetic acid (5-HIAA) (not present in tissue slice preparations). Using a combination of the Jackson waveform and electrodeposition of Nafion $^{\text {TM }}$, they were able to measure $5-\mathrm{HT}$ in vivo in the rat $\mathrm{SNr}^{139}$ The following section details recent keynote studies utilizing 5HT FSCV in physiological investigations.

\section{Serotonin's role in affective disorders}

Diagnosis of affective (mood) disorders would greatly benefit from electrochemical $5-\mathrm{HT}$ detection. $5-\mathrm{HT}$ is thought to modulate mood; it has long been postulated that 5-HT deficiency underlies the behavioral phenotypes of affective disorders such as depression. ${ }^{159}$ However, this hypothesis (the monoamine theory of depression) has been difficult to verify because of the challenge of measuring $5-\mathrm{HT}$ in vivo on neurotransmission timescales. Using FSCV it is now possible to measure 5-HT with high temporal and spatial resolution in vivo. This has strengthened our knowledge of 5-HT physiology and pharmacology, as reviewed below, and will ultimately enable characterization of 5-HT in affective disease models.

In 2014, Wood et al. found that 5-HT in the mouse SNr had three uptake profiles: slow ( $>20$ seconds), fast ( $<10$ seconds), and hybrid (a combination of the slow and fast), with the hybrid mechanism being the most common of the uptake profile encountered in vivo. ${ }^{160}$ The 'fast' and 'slow' responses were identified as two distinct clearance mechanisms: Uptake 1 (slow), mediated by the SERTs, and Uptake 2 (fast), mediated by other monoamine transporters (DATs, NETs, and OCTs). This study also found that the electrical stimulation created autoreceptor inhibition of 5-HT that lasted tens of seconds. ${ }^{160}$ West et al. observed a "double peak" phenomenon in the mouse medial prefrontal cortex (mPFC) (Fig. 8), ${ }^{161}$ in which two 5-HT events were released upon electrical stimulation of the medial

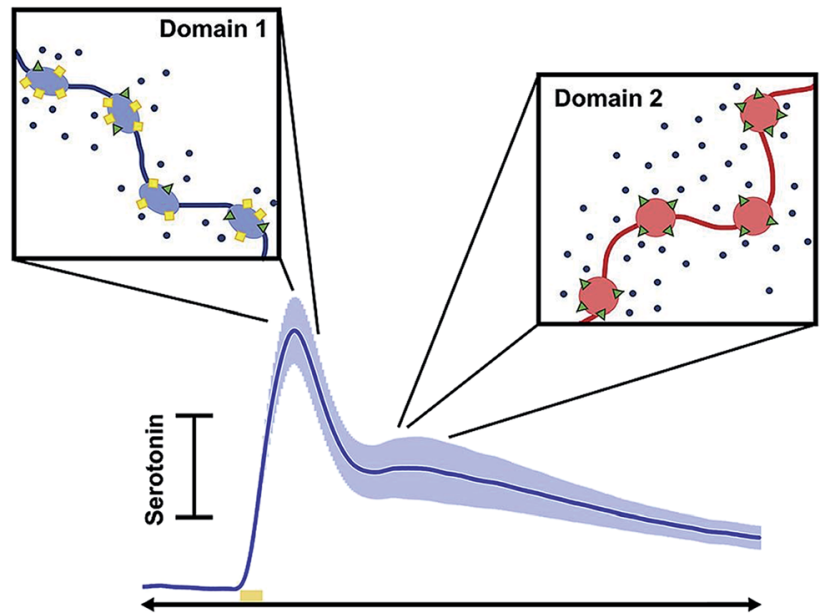

Fig. 8 Schematic showing how each peak in the current vs. time trace corresponds to different uptake mechanisms. Reproduced with permission from West, A., et al. ${ }^{161}$

forebrain bundle (MFB). This is in contrast to the one evoked peak typically seen in other brain regions. ${ }^{160,162}$ Consistently, layers $1-3$ of the mPFC produced a single evoked peak, whereas layers 5 and 6 produced a double peak. ${ }^{161}$ The authors hypothesized two types of 5-HT input to the terminal, linked to discrete reuptake domains. An example of the double peak and the discrete reuptake domains are shown in Fig. 8.

Extracellular 5-HT is thought to be lower during depression, ${ }^{163}$ therefore selective 5 -HT reuptake inhibitors (SSRIs), which inhibit the SERTs (presumably increasing extracellular 5HT levels) are a common treatment. Wood and Hashemi administered acute doses of a common SSRI, escitalopram, to mice. The group found that the effects of this drug on 5-HT were dynamic, not reaching a steady state before drug metabolism. ${ }^{164}$ This study suggested that dose-response curves should be redesigned. The Wightman group investigated the effects of SSRIs on autoreceptor-mediated inhibitory feedback and showed involvement of multiple modulatory mechanisms in response to the SSRI. ${ }^{165}$ These studies clearly show that SSRI effects on the 5-HT system are complex and in need of further study.

While in vivo 5-HT FSCV studies are ongoing recent technical advancements including spatial improvements, simultaneous detection of analytes and ambient 5-HT measurements are enriching the chemical toolbox with which 5-HT can be studied.

\section{Novel technical advancements for serotonin measurements}

Serotonin measurements on a nano level. In vivo, CFMs are thought to measure from hundreds of synapses. ${ }^{166}$ CFMs are too large to probe events ex vivo from single synapses. As discussed above for ACh, the Shen lab's nanopipette-based liquid-liquid interface probes are $7-35 \mathrm{~nm}$ in radius and can thus probe single synapses. ${ }^{\mathbf{8 1}}$ For 5-HT detection, the nanopipettes were filled with an organic phase, 1,2-dichloroethane. ${ }^{81}$ Upon the application of a potential, 5-HT was transferred across the ITIES tip into the organic phase. The authors observed that a higher overpotential 
was required for transferring 5 - $\mathrm{HT}$ across the interface compared to tryptamine so the detection of lower concentrations of 5-HT proved to be more difficult. Nonetheless, the authors achieved a limit of detection of $77 \mu \mathrm{M}$ with a $21 \mathrm{~nm}$ pipette, which is likely sufficient for synaptic measurements.

Simultaneously measuring serotonin with other analytes. An important recent finding is 5-HT's co-modulatory relationship with HA. The axons of these two modulatory systems are highly colocalized, ${ }^{167,168}$ and prior ex vivo chemical measurements implied co-modulation. ${ }^{\mathbf{1 6 9 - 1 7 1}} \mathrm{HA}$ measurements are challenging, since HA electrooxidation is not straightforward and likely involves charge transfer. ${ }^{172}$ Samaranayake et al. optimized a waveform that enabled a robust, faradaic oxidation peak in response to HA with an LOD of $1 \mu \mathrm{M}$ and linear dynamic range spanned up to $20 \mu \mathrm{M}$. This was sufficient for measuring HA in vivo. ${ }^{172}$ Further experiments used this waveform to understand the modulation of 5-HT and HA in vivo. The group showed that 5HT was inhibited by $\mathrm{H}_{3}$ heteroreceptors on post synaptic neurons. ${ }^{172}$ Fig. 9 shows that 5 -HT release is inhibited by HA even under varying factors including the stimulation frequency (Fig. 9C), the stimulation pulse width (Fig. 9D) and the stimulation amplitude (Fig. 9E).

Other notable studies include the WINCS Harmoni wireless device created by Lee et al. ${ }^{\mathbf{1 4 8}}$ that simultaneously detects 5-HT in the $\mathrm{SNr}$ and DA in the striatum. More details on WINCS Harmoni can be found in the DA section of this review (vide supra). The Dayan lab created a mathematical algorithm capable of separating DA and 5-HT signals in humans. ${ }^{173}$ Finally, the Cai and Liu labs are working on electrochemical arrays with the capability of measuring 5-HT with other analyte and the potential for future in vivo analysis. ${ }^{\mathbf{1 7 4 , 1 7 5}}$

Ambient, steady-state serotonin measurements. As described above, FSCV is background subtracted, thus basal or ambient, steady state 5-HT values cannot be garnered with this method. Abdalla et al. optimized FSCAV for 5-HT measurements and reported basal levels of 5 -HT in the CA2 region of the hippocampus as $64.9 \pm 2.3 \mathrm{nM}$ in vivo. ${ }^{162}$ The technique shows linearity up to $600 \mathrm{nM}$ with an LOD of $1.5 \mathrm{nM}$. Instrumentation for FSCAV has recently been simplified such that it can be constructed by non-experts with simple electrical components. ${ }^{\mathbf{1 7 6}}$

\section{Other neurochemicals}

As the community develops better tools for defining the roles of neurotransmitters in disease, we can better focus diagnostic tests on neurotransmitters specific to distinct disorders. GABA is the most abundant inhibitory neurotransmitter. ${ }^{177}$ Because GABA is not easily redox active, electrochemical analysis of this neurotransmitter is challenging. ${ }^{178}$ The Shen lab applied their nanopipette approach to GABA. ${ }^{179}$ Unlike the analytes reviewed here, GABA is a zwitterion at neutral pH; this phenomenon makes it very difficult to partition GABA between phases. To
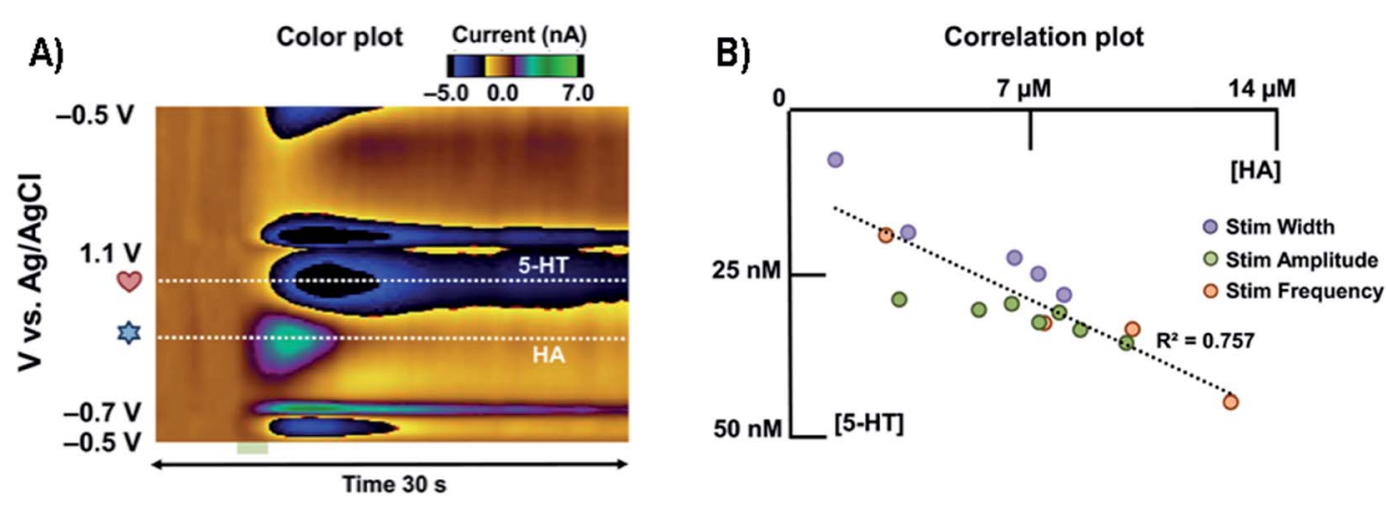

C) Stimulation frequency

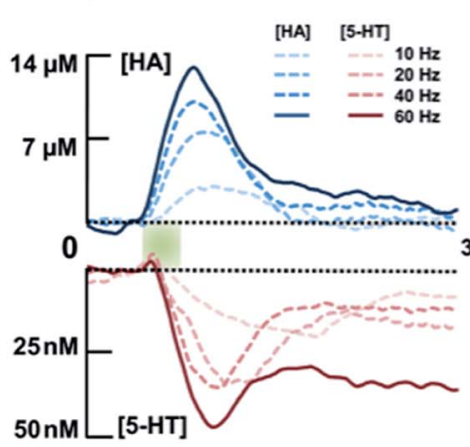

D) Stimulation pulse width
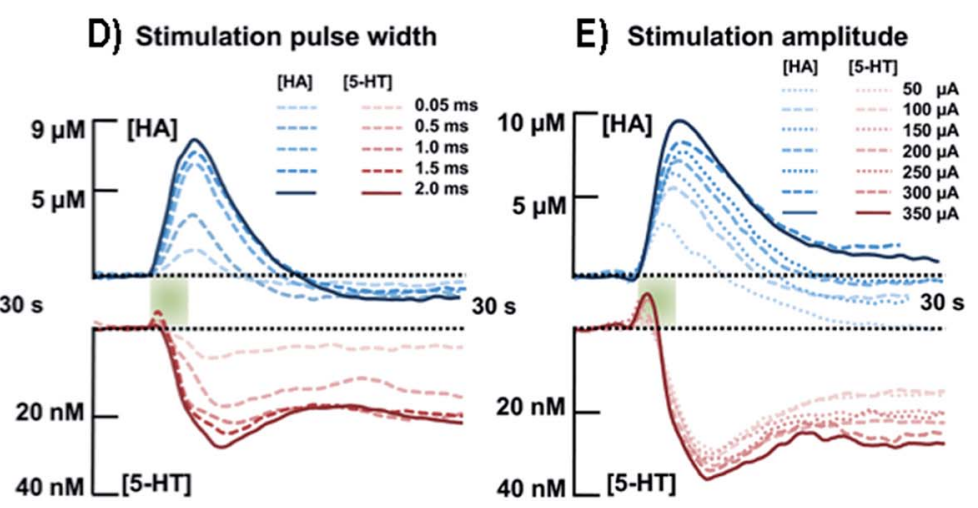

Fig. 9 (A) Representative color plot of the stimulated release of $\mathrm{HA}$ and 5-HT inhibition in the premammillary nucleus. (B) Correlation plot between $[\mathrm{HA}]$ and $[5-\mathrm{HT}]$ for all stimulation parameters. (C) Averaged current versus time traces along the two horizontal dashed lines of $\mathrm{HA}$ and $5-\mathrm{HT}$ with respect to different stimulation frequencies $(n=5)$. (D) Averaged current responses to various stimulation pulse widths of HA and 5 - HT $(n=5)$. (E) Averaged current responses to various stimulation amplitudes of HA and 5-HT $(n=5)$. HA, HA; 5-HT, 5-HT. Reproduced from Samaranayake et al. with permission. ${ }^{172}$ 
facilitate partitioning between phases, octanoic acid was added to lower the $\mathrm{pH}$ along with dibenzo-18-crown-6, thus detection of protonated GABA. ${ }^{179}$ The Arumugam lab took an interesting electrochemical approach to detecting GABA simultaneously with Glu using a microarray with GABA and Glu biosensors. On site 1 of the array is a Glu biosensor and on site 2 is a GABA biosensor side-by-side with a second Glu biosensor. The group measured the current generated from $\mathrm{H}_{2} \mathrm{O}_{2}$ oxidation at both electrodes. The current at site 1 was due to Glu only. The current at site 2 was due to Glu and GABA, therefore subtraction of site 1 current from site 2 allowed GABA quantification. ${ }^{\mathbf{1 8 0}}$

Peptides are strings of amino acids that act as signaling molecules in the brain. The Sombers lab created a sawhorse FSCV waveform to detect Met-enkephalins. The detection scheme is shown in Fig. 10. The sawhorse FSCV waveform (Fig. 10B) is modified from the conventional one used for DA detection (Fig. 10A). Using the conventional waveform produced significant electrode fouling (Fig. 10C, asterisk), which was not observed in the color plot for modified sawhorse waveform. Their method has high selectivity, being able to distinguish Leu- and Metenkephalin, which differ by a single amino acid. ${ }^{181}$ The group successfully measured norepinephrine and Met-enkephalin release after mild electrical stimulation in adrenal tissue slice.

The Venton group has been successful at measuring a variety of neurotransmitters including octopamine and adenosine. ${ }^{\mathbf{1 8 2 - 1 8 4}}$ Octopamine is a biogenic amine in invertebrates that regulates intracellular cyclic AMP (adenosine monophosphate) and $\mathrm{Ca}^{2+} \cdot{ }^{185}$ Pyakurel et al. first measured octopamine using FSCV in the ventral nerve cord of Drosophilia melanogaster larvae. ${ }^{\mathbf{1 8 2}}$ Octopamine was released via optogenetic red light-stimulated release with a total simulation time of $1 \mathrm{~s}$ or less. ${ }^{182}$ Adenosine is a nucleoside produced from the breakdown of ATP. In the central nervous system, this molecule plays an important role in many biological processes, such as regulating neurotransmission and reducing excitotoxicity. ${ }^{\mathbf{1 8 3}}$ Nguyen and Venton developed a method for direct adenosine detection using FSCV. ${ }^{183}$ Spontaneous adenosine transients were observed in addition to electrically and mechanically stimulated release. ${ }^{183}$ In vivo clearance of spontaneous adenosine was shown to occur through multiple mechanisms in the rat caudate putamen. ${ }^{\mathbf{1 8 4}}$ These mechanisms include reuptake through the equilibrative nucleoside transport 1 , as well as metabolism of adenosine by adenosine deaminase and adenosine kinase. ${ }^{\mathbf{1 8 4}}$ Ganesana et al. examined spontaneous adenosine transients during cerebral ischemia. ${ }^{186}$ They found a $52 \%$ increase in the number of adenosine transients and a 53\% increase in cumulative adenosine concentration during the early stages of cerebral ischemia as compared to normoxia control rats. ${ }^{186}$ Another group that studied adenosine developed synthetic boron-doped diamondbased electrodes for chronic in vivo measurements of adenosine in humans undergoing deep brain stimulation ${ }^{\mathbf{1 8 7}}$ surgeries for tremor treatment. These diamond-based electrodes, showing little to no degradation even after 5.2 million cycles of FSCV experiments (144 h at $10 \mathrm{~Hz}$ ), are two-orders of magnitude more robust than carbon fiber-based electrodes. ${ }^{187}$
A Conventional Waveform

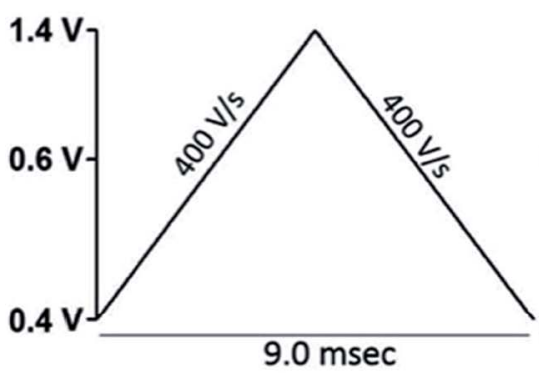

C

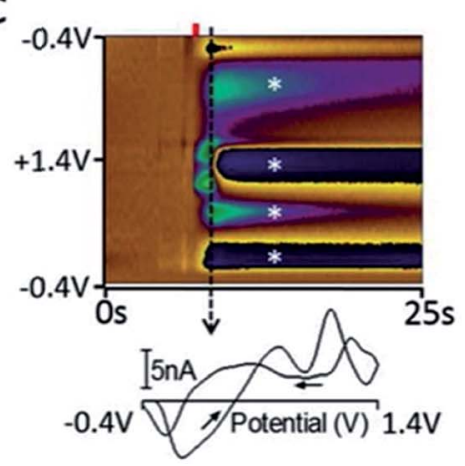

B Modified Sawhorse Waveform (MSW)
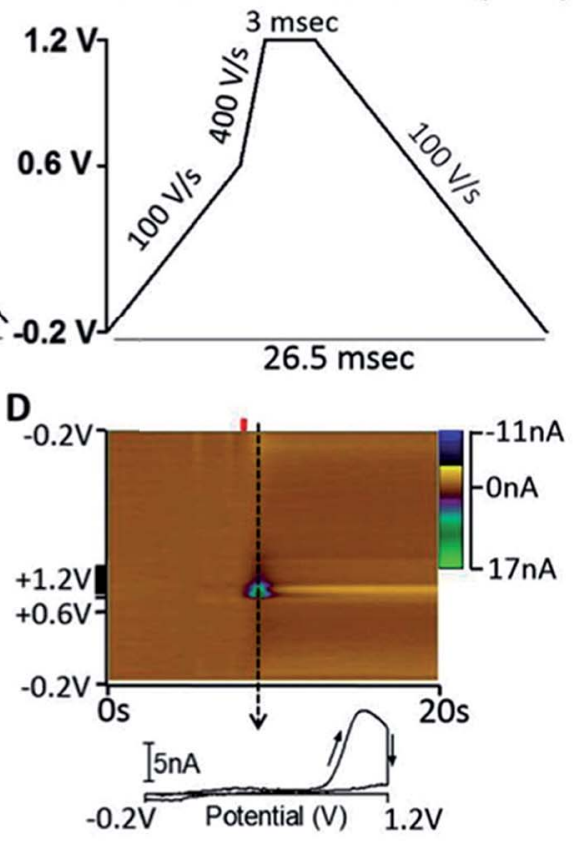

Fig. 10 (A) Triangular waveform. (B) Modified sawhorse waveform (MSW). (C and D) Representative in vitro voltammetric data collected using the waveforms depicted in parts $A$ and $B$, respectively, where the ordinate is the potential applied to the carbon-fiber electrode, the abscissa is time in seconds, and the current $(\mathrm{nA})$ is depicted in false color. ${ }^{55} 2 \mu \mathrm{M} \mathrm{M}$-ENK was introduced to the microelectrode at the time indicated by the red bar. Displayed voltammograms were extracted at the time indicated by the dashed line. Asterisks indicate electrode fouling. Reproduced with permission from Schmidt et al. ${ }^{181}$ 
Melatonin is a hormone produced by the pineal gland and lymph nodes ${ }^{\mathbf{1 8 8}}$ and is thought to play a role in regulating circadian rhythm. ${ }^{189}$ The Ross lab developed a new waveform to selectively detect melatonin and to reduce fouling otherwise observed with conventional waveforms. ${ }^{190}$ The authors successfully used this new waveform for melatonin detection in lymph node tissue slice preparations. ${ }^{190}$ In a similar approach, the same group developed a novel waveform for detection of the neuromodulator guanosine. ${ }^{191}$ Their optimized approach was selective for guanosine over adenosine because two oxidation events were observed for guanosine at $+0.8 \mathrm{~V}$ and $+1.3 \mathrm{~V}$. This method was successfully applied to measuring exogenously applied guanosine in tissue slice preparations. ${ }^{191}$

\section{Conclusion and future direction}

Neurochemical diagnosis for brain disorders is not available due to a lack of in vivo sensors capable of monitoring neurotransmitters and neuromodulators. This review highlighted advancements made in the field of electrochemical microdevices over the past five years for detection and quantification of neurochemical biomarkers of brain disorders. The potential for these analytes to act as biomarkers was discussed and novel measurement methods were highlighted. Specifically, we began each neurotransmitter section with a discussion of what we have learned thus far about the role of each of them in various applicable brain physiology using existing and emerging electrochemical techniques. We then focused on emerging biosensor technology for Glu and 5-HT detection and voltammetric methods for DA and 5HT measurements. We ended the review with discussion about other neuromodulators of interest, e.g. peptides, adenosine, etc., and what tools were designed to measure them.

Via this review we highlighted the considerable progress made thus far in the field of electrochemical sensing for in vivo neurotransmitters. However, there are still challenges that need to be addressed when moving towards diagnostic devices. First, probe size remains problematic. Implantation is a physical perturbation to brain tissue. Ongoing efforts to make probe sizes comparable to interneuron distances will minimize damage and reduce inflammation. Furthermore, ongoing miniaturization to nanometer scales will allow synaptic measurements. Second, electrochemical sensing is limited to a few electroactive species. Peptides and proteins still evade detection via electrochemical sensors and thus cannot be measured with the same spatiotemporal resolution as smaller, more classical neuromodulators. Future horizons for this type of work may include aptamer modifications to electrodes. Lastly, and perhaps the most significant, there exist no clinical measurements in humans but we are confident, due to the rapid progress in the field reviewed here, that such measurements will be facilitated in the near future.

\section{List of abbreviations}

$\begin{array}{ll}\text { Glu } & \text { Glutamate } \\ \text { DA } & \text { Dopamine }\end{array}$
Ach Acetylcholine
5-HT Serotonin
HA Histamine
GABA Gamma-aminobutyric acid
DNA Deoxyribonucleic acid
NDMA $N$-Methyl-D-aspartate
AMPA $\alpha$-Amino-3-hydroxy-5-methyl-4-isoxazole-propionic acid
PFC Prefrontal cortex
mPFC Medial prefrontal cortex
AA Ascorbic acid
ITIES Interface between two immiscible electrolyte solutions
CFMs Carbon fiber microelectrodes
FSCV Fast scan cyclic voltammetry
FSCAV Fast scan controlled adsorption voltammetry
WINCS Wireless instantaneous neurotransmitter
concentration sensing
SNr Substantia nigra pars reticulata
DANA Dopamine and neural activity
SD Spreading depolarization
5-HTP 5-Hydroxytryptophan
5-HIAA 5-Hydroxyindoleacetic acid
SERTs Selective serotonin reuptake inhibitors
DATs Dopamine transporters
NETs Norepinephrine transporters
OCTs Organic cation transporters

\section{Conflicts of interest}

There are no conflicts to declare.

\section{Acknowledgements}

The authors would like to thank Jordan Holmes for making the neurotransmitter molecules and both Jordan Holmes and Shane Berger for their contributions to the TOC image. The National Institutes of Health (R01 MH106563 for P. H.) funded this work.

\section{References}

1 M. Oaklander, Time Magazine, 2017, 190, 38-45.

2 F. A. Settle, Handbook of instrumental techniques for analytical chemistry, Prentice Hall PTR, Upper Saddle River, NJ, 1997.

3 E. Dankoski and R. Wightman, Front. Integr. Neurosci., 2013, 7,44 .

4 A. Jaquins-Gerstl and A. C. Michael, Analyst, 2015, 140, 3696-3708.

5 S. V. Dzyadevych, V. N. Arkhypova, A. P. Soldatkin, A. V. El'skaya, C. Martelet and N. Jaffrezic-Renault, IRBM, 2008, 29, 171-180.

6 T. D. Y. Kozai, A. S. Jaquins-Gerstl, A. L. Vazquez, A. C. Michael and X. T. Cui, ACS Chem. Neurosci., 2015, 6, 48-67.

7 W. Putzbach and J. N. Ronkainen, Sensors, 2013, 13, 48114840. 
8 D. C. Javitt, Mol. Psychiatry, 2004, 9, 984.

9 B. S. Meldrum, J. Nutr., 2000, 130, 1007S-1015S.

10 E. E. Benarroch, Neurology, 2010, 74, 259.

11 Y. Zhou and N. C. Danbolt, J. Neural Transm., 2014, 121, 799-817.

12 H. Kusakabe, Y. Midorikawa, T. Fujishima, A. Kuninaka and H. Yoshino, Agric. Biol. Chem., 1983, 47, 1323-1328.

13 N. V. Kulagina, L. Shankar and A. C. Michael, Anal. Chem., 1999, 71, 5093-5100.

$14 \mathrm{~J} . \mathrm{Hu}, \mathrm{S}$. Wisetsuwannaphum and J. S. Foord, Faraday Discuss., 2014, 172, 457-472.

15 O. Frey, T. Holtzman, R. M. McNamara, D. E. H. Theobald, P. D. van der Wal, N. F. de Rooij, J. W. Dalley and M. Koudelka-Hep, Biosens. Bioelectron., 2010, 26, 477-484.

16 A. Weltin, J. Kieninger and G. A. Urban, Anal. Bioanal. Chem., 2016, 408, 4503-4521.

17 N. Vasylieva, C. Maucler, A. Meiller, H. Viscogliosi, T. Lieutaud, D. Barbier and S. Marinesco, Anal. Chem., 2013, 85, 2507-2515.

18 W. H. Scouten, J. H. T. Luong and R. Stephen Brown, Trends Biotechnol., 1995, 13, 178-185.

19 R. S. Freire, C. A. Pessoa, L. D. Mello and L. T. Kubota, J. Braz. Chem. Soc., 2003, 14, 230-243.

20 W. Putzbach and N. J. Ronkainen, Sensors, 2013, 13, 48114840.

21 G. Hughes, R. M. Pemberton, P. R. Fielden and J. P. Hart, TrAC, Trends Anal. Chem., 2016, 79, 106-113.

22 G. Bidan, Sens. Actuators, B, 1992, 6, 45-56.

23 P. N. Bartlett and J. M. Cooper, J. Electroanal. Chem., 1993, 362, 1-12.

24 F. Palmisano, D. Centonze, A. Guerrieri and P. G. Zambonin, Biosens. Bioelectron., 1993, 8, 393-399.

25 S. A. Emr and A. M. Yacynych, Electroanalysis, 1995, 7, 913923.

26 M. Trojanowicz and T. K. vel Krawczyk, Microchim. Acta, 1995, 121, 167-181.

27 N. Wahono, S. Qin, P. Oomen, T. I. F. Cremers, M. G. de Vries and B. H. C. Westerink, Biosens. Bioelectron., 2012, 33, 260-266.

28 A. Witkowski and A. Brajter-Toth, Anal. Chem., 1992, 64, 635-641.

29 N. Hamdi, J. Wang, E. Walker, N. T. Maidment and H. G. Monbouquette, J. Electroanal. Chem., 2006, 591, 3340.

30 N. Hamdi, J. Wang and H. G. Monbouquette, J. Electroanal. Chem., 2005, 581, 258-264.

31 A. Morales-Villagrán, L. Medina-Ceja and S. J. López-Pérez, J. Neurosci. Methods, 2008, 168, 48-53.

32 K. M. Wassum, V. M. Tolosa, J. Wang, E. Walker, H. G. Monbouquette and N. T. Maidment, Sensors, 2008, 8, 5023-5036.

33 K. M. Wassum, V. M. Tolosa, T. C. Tseng, B. W. Balleine, H. G. Monbouquette and N. T. Maidment, J. Neurosci., 2012, 32, 2734.

34 V. M. Tolosa, K. M. Wassum, N. T. Maidment and H. G. Monbouquette, Biosens. Bioelectron., 2013, 42, 256260.
35 J. J. Burmeister and G. A. Gerhardt, Anal. Chem., 2001, 73, 1037-1042.

36 E. S. McLamore, S. Mohanty, J. Shi, J. Claussen, S. S. Jedlicka, J. L. Rickus and D. M. Porterfield, J. Neurosci. Methods, 2010, 189, 14-22.

37 H. Boo, R.-A. Jeong, S. Park, K. S. Kim, K. H. An, Y. H. Lee, J. H. Han, H. C. Kim and T. D. Chung, Anal. Chem., 2006, 78, 617-620.

38 A. Gholizadeh, S. Shahrokhian, A. Iraji zad, S. Mohajerzadeh, M. Vosoughi, S. Darbari and Z. Sanaee, Biosens. Bioelectron., 2012, 31, 110-115.

39 A. Gholizadeh, S. Shahrokhian, A. Iraji zad, S. Mohajerzadeh, M. Vosoughi, S. Darbari, J. Koohsorkhi and M. Mehran, Anal. Chem., 2012, 84, 5932-5938.

40 R. S. Dey, R. K. Bera and C. R. Raj, Anal. Bioanal. Chem., 2013, 405, 3431-3448.

41 F. Ricci and G. Palleschi, Biosens. Bioelectron., 2005, 21, 389-407.

42 F. Ricci, A. Amine, D. Moscone and G. Palleschi, Biosens. Bioelectron., 2007, 22, 854-862.

43 S. Qin, M. Van der Zeyden, H. W. Oldenziel, I. T. Cremers and H. B. Westerink, Sensors, 2008, 8, 6860-6884.

44 S. K. Hamdan and A. Mohd Zain, Malays. J. Med. Sci., 2014, 21, 12-26.

45 E. Naylor, D. V. Aillon, S. Gabbert, H. Harmon, D. A. Johnson, G. S. Wilson and P. A. Petillo, J. Electroanal. Chem., 2011, 656, 106-113.

46 M. V. Johnston, S. Ammanuel, C. O'Driscoll, A. Wozniak, S. Naidu and S. D. Kadam, Front. Syst. Neurosci., 2014, 8, 118.

47 M. Lenoir and E. A. Kiyatkin, J. Neurochem., 2013, 127, 541551.

48 K. T. Wakabayashi and E. A. Kiyatkin, J. Neurophysiol., 2012, 108, 285-299.

49 M. A. Rahman, N.-H. Kwon, M.-S. Won, E. S. Choe and Y.-B. Shim, Anal. Chem., 2005, 77, 4854-4860.

50 M. Malvaez, V. Y. Greenfield, A. S. Wang, A. M. Yorita, L. Feng, K. E. Linker, H. G. Monbouquette and K. M. Wassum, Sci. Rep., 2015, 5, 12511.

51 M. D. Scofield, H. A. Boger, R. J. Smith, H. Li, P. G. Haydon and P. W. Kalivas, Biol. Psychiatry, 2015, 78, 441-451.

52 R. E. Özel, C. Ispas, M. Ganesana, J. C. Leiter and S. Andreescu, Biosens. Bioelectron., 2014, 52, 397-402.

53 W. Shi, N. Lin, Y. Song, C. Liu, S. Zhou and X. Cai, Biosens. Bioelectron., 2014, 51, 244-248.

54 T. T. Tseng, C.-F. Chang and W.-C. Chan, Molecules, 2014, 19, 7341-7355.

55 A. Weltin, J. Kieninger, B. Enderle, A.-K. Gellner, B. Fritsch and G. A. Urban, Biosens. Bioelectron., 2014, 61, 192-199.

56 A. Weltin, B. Enderle, J. Kieninger and G. A. Urban, IEEE Sens. J., 2014, 14, 3345-3351.

57 M. Clay and H. G. Monbouquette, ACS Chem. Neurosci., 2018, 9, 241-251.

58 S. Sainio, T. Palomäki, N. Tujunen, V. Protopopova, J. Koehne, K. Kordas, J. Koskinen, M. Meyyappan and T. Laurila, Mol. Neurobiol., 2015, 52, 859-866. 
59 B. Nasr, R. Chatterton, J. H. M. Yong, P. Jamshidi, G. M. D'Abaco, A. R. Bjorksten, O. Kavehei, G. Chana, M. Dottori and E. Skafidas, Biosensors, 2018, 8, 14.

60 M. Jamal, S. Chakrabarty, M. A. Yousuf, A. Khosla and K. M. Razeeb, Microsyst. Technol., 2018, 24, 4193-4206.

$61 \mathrm{H}$. Yu, Z. Ma and Z. Wu, Anal. Chim. Acta, 2015, 896, 137142.

62 B. Liang, S. Zhang, Q. Lang, J. Song, L. Han and A. Liu, Anal. Chim. Acta, 2015, 884, 83-89.

63 G. Hughes, R. M. Pemberton, P. R. Fielden and J. P. Hart, Sens. Actuators, B, 2015, 216, 614-621.

64 F. Wu, P. Yu, X. Yang, Z. Han, M. Wang and L. Mao, J. Am. Chem. Soc., 2018, 140, 12700-12704.

65 K. M. Moore, B. T. Himmler, B. A. Teplitzky, M. D. Johnson and R. L. Meisel, J. Visualized Exp., 2017, 56135, DOI: $10.3791 / 56135$.

66 G. Massicotte, S. Carrara, G. Di Micheli and M. Sawan, IEEE Trans. Biomed. Circuits Syst., 2016, 10, 731-741.

67 N. R. Ferreira, A. Ledo, J. Laranjinha, G. A. Gerhardt and R. M. Barbosa, Bioelectrochemistry, 2018, 121, 142-150.

68 W. Wei, Y. Song, L. Wang, S. Zhang, J. Luo, S. Xu and X. Cai, Microsyst. Nanoeng., 2015, 1, 15002.

69 X. Fan, Y. Song, Y. Ma, S. Zhang, G. Xiao, L. Yang, H. Xu, D. Zhang and X. Cai, Sensors, 2016, 17, 61.

70 M. R. Picciotto, M. J. Higley and Y. S. Mineur, Neuron, 2012, 76, 116-129.

71 M. G. Garguilo and A. C. Michael, TrAC, Trends Anal. Chem., 1995, 14, 164-169.

72 K. M. Mitchell, Anal. Chem., 2004, 76, 1098-1106.

73 J. P. Bruno, C. Gash, B. Martin, A. Zmarowski, F. Pomerleau, J. Burmeister, P. Huettl and G. A. Gerhardt, Eur. J. Neurosci., 2006, 24, 2749-2757.

74 J. J. Burmeister, F. Pomerleau, P. Huettl, C. R. Gash, C. E. Werner, J. P. Bruno and G. A. Gerhardt, Biosens. Bioelectron., 2008, 23, 1382-1389.

75 V. Parikh, F. Pomerleau, P. Huettl, G. A. Gerhardt, M. Sarter and J. P. Bruno, Eur. J. Neurosci., 2004, 20, 1545-1554.

76 J. J. Burmeister, M. Palmer and G. A. Gerhardt, Anal. Chim. Acta, 2003, 481, 65-74.

77 W. M. Howe, A. S. Berry, J. Francois, G. Gilmour, J. M. Carp, M. Tricklebank, C. Lustig and M. Sarter, J. Neurosci., 2013, 33, 8742 .

78 H. J. Gritton, W. M. Howe, C. S. Mallory, V. L. Hetrick, J. D. Berke and M. Sarter, Proc. Natl. Acad. Sci. U. S. A., 2016, 113, E1089-E1097.

79 W. M. Howe, H. J. Gritton, N. A. Lusk, E. A. Roberts, V. L. Hetrick, J. D. Berke and M. Sarter, J. Neurosci., 2017, 37, 3215-3230.

80 L. M. Teles-Grilo Ruivo, K. L. Baker, M. W. Conway, P. J. Kinsley, G. Gilmour, K. G. Phillips, J. T. R. Isaac, J. P. Lowry and J. R. Mellor, Cell Rep., 2017, 18, 905-917.

81 M. L. Colombo, J. V. Sweedler and M. Shen, Anal. Chem., 2015, 87, 5095-5100.

82 T. M. Welle, K. Alanis, M. L. Colombo, J. V. Sweedler and M. Shen, Chem. Sci., 2018, 9, 4937-4941.

83 M. Shen, Z. Qu, J. T. DesLaurier, T. M. Welle, J. V. Sweedler and R. Chen, J. Am. Chem. Soc., 2018, 140, 7764-7768.
84 K. L. Baker, F. B. Bolger and J. P. Lowry, Analyst, 2015, 140, 3738-3745.

85 F. E. Kanik, M. Kolb, S. Timur, M. Bahadir and L. Toppare, Int. J. Biol. Macromol., 2013, 59, 111-118.

86 J.-R. Cai, L.-N. Zhou and E. Han, Anal. Sci., 2014, 30, 669673.

87 T. Itoh, T. Shimomura, A. Hayashi, A. Yamaguchi, N. Teramae, M. Ono, T. Tsunoda, F. Mizukami, G. D. Stucky and T.-a. Hanaoka, Analyst, 2014, 139, 4654-4660.

88 N. Chauhan, J. Narang and U. Jain, Analyst, 2015, 140, 19881994.

89 R. M. Santos, J. Laranjinha, R. M. Barbosa and A. Sirota, Biosens. Bioelectron., 2015, 69, 83-94.

90 M. P. S. Mousavi, M. K. Abd El-Rahman, A. M. Mahmoud, R. M. Abdelsalam and P. Bühlmann, ACS Sens., 2018, 3, 2581-2589.

91 J. D. Keighron, J. Wigström, M. E. Kurczy, J. Bergman, Y. Wang and A.-S. Cans, ACS Chem. Neurosci., 2015, 6, 181-188.

92 Y. Zhang, M. A. Arugula, J. S. Kirsch, X. Yang, E. Olsen and A. L. Simonian, Langmuir, 2015, 31, 1462-1468.

93 P. Monti, G. Calia, S. Marceddu, M. A. Dettori, D. Fabbri, S. Jaoua, R. D. O'Neill, Q. Migheli, G. Delogu and P. A. Serra, Talanta, 2017, 162, 151-158.

94 N. Chauhan and C. S. Pundir, Biosens. Bioelectron., 2014, 61, 1-8.

95 N. Chauhan, S. Chawla, C. S. Pundir and U. Jain, Biosens. Bioelectron., 2017, 89, 377-383.

96 D. Sulzer, S. J. Cragg and M. E. Rice, Basal Ganglia, 2016, 6, 123-148.

97 A. G. Ewing, R. M. Wightman and M. A. Dayton, Brain Res., 1982, 249, 361-370.

98 R. M. Wightman, L. J. May and A. C. Michael, Anal. Chem., 1988, 60, 769A-793A.

99 M. L. A. V. Heien, P. E. M. Phillips, G. D. Stuber, A. T. Seipel and R. M. Wightman, Analyst, 2003, 128, 1413-1419.

100 P. Takmakov, M. K. Zachek, R. B. Keithley, P. L. Walsh, C. Donley, G. S. McCarty and R. M. Wightman, Anal. Chem., 2010, 82, 2020-2028.

101 J. O. Schenk, E. Miller, M. E. Rice and R. N. Adams, Brain Res., 1983, 277, 1-8.

102 B. J. Venton and R. M. Wightman, Anal. Chem., 2003, 75, 414A-421A.

103 P. M. Kovach, A. G. Ewing, R. L. Wilson and R. M. Wightman, J. Neurosci. Methods, 1984, 10, 215-227.

104 J. O. Howell, W. G. Kuhr, R. E. Ensman and R. M. Wightman, J. Electroanal. Chem. Interfacial Electrochem., 1986, 209, 77-90.

105 W. G. Kuhr and R. M. Wightman, Brain Res., 1986, 381, 168171.

106 G. V. Rebec, J. R. C. Christensen, C. Guerra and M. T. Bardo, Brain Res., 1997, 776, 61-67.

107 P. E. M. Phillips, G. D. Stuber, M. L. A. V. Heien, R. M. Wightman and R. M. Carelli, Nature, 2003, 422, 614.

108 C. A. Owesson-White, J. F. Cheer, M. Beyene, R. M. Carelli and R. M. Wightman, Proc. Natl. Acad. Sci. U. S. A., 2008, 105, 11957. 
109 S. B. Flagel, J. J. Clark, T. E. Robinson, L. Mayo, A. Czuj, I. Willuhn, C. A. Akers, S. M. Clinton, P. E. M. Phillips and H. Akil, Nature, 2010, 469, 53.

110 M. W. Howe, P. L. Tierney, S. G. Sandberg, P. E. M. Phillips and A. M. Graybiel, Nature, 2013, 500, 575.

111 C. M. Cameron, R. M. Wightman and R. M. Carelli, Neuropharmacology, 2016, 111, 223-230.

112 A. K. Radke, A. Kocharian, D. P. Covey, D. M. Lovinger, J. F. Cheer, Y. Mateo and A. Holmes, Eur. J. Neurosci., 2018, DOI: 10.1111/ejn.14152.

113 K. J. Pultorak, S. A. Schelp, D. P. Isaacs, G. Krzystyniak and E. B. Oleson, eNeuro, 2018, 5, DOI: 10.1523/ENEURO.00581518.2018.

114 J. M. Wenzel, E. B. Oleson, W. N. Gove, A. B. Cole, U. Gyawali, H. M. Dantrassy, R. J. Bluett, D. I. Dryanovski, G. D. Stuber and K. Deisseroth, Curr. Biol., 2018, 28, 1392-1404.

115 R. N. Gentry, D. R. Schuweiler and M. R. Roesch, Brain Res., 2018, DOI: 10.1016/j.brainres.2018.1010.1008.

116 L. Naef, L. Seabrook, J. Hsiao, C. Li and S. L. Borgland, Eur. J. Neurosci., 2018, DOI: 10.1111/ejn.14291.

117 E. S. Calipari, B. Juarez, C. Morel, D. M. Walker, M. E. Cahill, E. Ribeiro, C. Roman-Ortiz, C. Ramakrishnan, K. Deisseroth, M.-H. Han and E. J. Nestler, Nat. Commun., 2017, 8, 13877.

118 E. N. Graf, R. A. Wheeler, D. A. Baker, A. L. Ebben, J. E. Hill, J. R. McReynolds, M. A. Robble, O. Vranjkovic, D. S. Wheeler, J. R. Mantsch and P. J. Gasser, J. Neurosci., 2013, 33, 11800.

119 K. T. Kishida, I. Saez, T. Lohrenz, M. R. Witcher, A. W. Laxton, S. B. Tatter, J. P. White, T. L. Ellis, P. E. M. Phillips and P. R. Montague, Proc. Natl. Acad. Sci. U. S. A., 2016, 113, 200.

120 M. Shin, T. M. Field, C. S. Stucky, M. N. Furgurson and M. A. Johnson, ACS Chem. Neurosci., 2017, 8, 1880-1888.

121 S. V. Kaplan, R. A. Limbocker, R. C. Gehringer, J. L. Divis, G. L. Osterhaus, M. D. Newby, M. J. Sofis, D. P. Jarmolowicz, B. D. Newman and T. A. Mathews, ACS Chem. Neurosci., 2016, 7, 689-699.

122 T. M. Field, M. Shin, C. S. Stucky, J. Loomis and M. A. Johnson, ChemPhysChem, 2018, 19, 1192-1196.

123 A. A. Feduccia, J. A. Simms, D. Mill, H. Y. Yi and S. E. Bartlett, Br. J. Pharmacol., 2014, 171, 3420-3431.

124 M. Spanos, X. Xie, J. Gras-Najjar, S. C. White and L. A. Sombers, ACS Chem. Neurosci., 2019, 10, 1497-1505.

125 J. G. Roberts, J. V. Toups, E. Eyualem, G. S. McCarty and L. A. Sombers, Anal. Chem., 2013, 85, 11568-11575.

126 D. R. Schuweiler, C. D. Howard, E. S. Ramsson and P. A. Garris, Anal. Chem., 2018, 90, 13434-13442.

127 C. J. Meunier, J. G. Roberts, G. S. McCarty and L. A. Sombers, ACS Chem. Neurosci., 2017, 8, 411-419.

128 N. T. Rodeberg, S. G. Sandberg, J. A. Johnson, P. E. M. Phillips and R. M. Wightman, ACS Chem. Neurosci., 2017, 8, 221-234.

129 S. Nimbalkar, E. Castagnola, A. Balasubramani, A. Scarpellini, S. Samejima, A. Khorasani, A. Boissenin,
S. Thongpang, C. Moritz and S. Kassegne, Sci. Rep., 2018, 8, 6958.

130 H. N. Schwerdt, M. Kim, E. Karasan, S. Amemori, D. Homma, H. Shimazu, T. Yoshida, R. Langer, A. M. Graybiel and M. J. Cima, In 2017 IEEE $30^{\text {th }}$ International Conference on Micro Electro Mechanical Systems (MEMS), IEEE, 2017, pp. 549-552.

131 H. N. Schwerdt, H. Shimazu, K.-i. Amemori, S. Amemori, P. L. Tierney, D. J. Gibson, S. Hong, T. Yoshida, R. Langer and M. J. Cima, Proc. Natl. Acad. Sci. U. S. A., 2017, 201713756.

132 C. A. Owesson-White, M. F. Roitman, L. A. Sombers, A. M. Belle, R. B. Keithley, J. L. Peele, R. M. Carelli and R. M. Wightman, J. Neurochem., 2012, 121, 252-262.

133 C. W. Atcherley, N. D. Laude, E. B. Monroe, K. M. Wood, P. Hashemi and M. L. Heien, ACS Chem. Neurosci., 2015, 6, 1509-1516.

134 C. W. Atcherley, K. M. Wood, K. L. Parent, P. Hashemi and M. L. Heien, Chem. Commun., 2015, 51, 2235-2238.

135 M. H. Burrell, C. W. Atcherley, M. L. Heien and J. Lipski, ACS Chem. Neurosci., 2015, 6, 1802-1812.

136 Y. Oh, C. Park, D. H. Kim, H. Shin, Y. M. Kang, M. DeWaele, J. Lee, H.-K. Min, C. D. Blaha, K. E. Bennet, I. Y. Kim, K. H. Lee and D. P. Jang, Anal. Chem., 2016, 88, 1096210970.

137 Y. Oh, M. L. Heien, C. Park, Y. M. Kang, J. Kim, S. L. Boschen, H. Shin, H. U. Cho, C. D. Blaha, K. E. Bennet, H. K. Lee, S. J. Jung, I. Y. Kim, K. H. Lee and D. P. Jang, Biosens. Bioelectron., 2018, 121, 174-182.

$138 \mathrm{~J}$. A. Johnson and R. M. Wightman, Electrochem. Soc. Interface, 2017, 26, 53-57.

139 P. Hashemi, E. C. Dankoski, J. Petrovic, R. B. Keithley and R. M. Wightman, Anal. Chem., 2009, 81, 9462-9471.

140 M. Spanos, J. Gras-Najjar, J. M. Letchworth, A. L. Sanford, J. V. Toups and L. A. Sombers, ACS Chem. Neurosci., 2013, 4, 782-789.

141 S. K. Smith, C. A. Lee, M. E. Dausch, B. M. Horman, H. B. Patisaul, G. S. McCarty and L. A. Sombers, ACS Chem. Neurosci., 2017, 8, 272-280.

142 J. Bergman, L. Mellander, Y. Wang and A.-S. Cans, Catalysts, 2018, 8, 34.

143 F. H. Cincotto, T. C. Canevari, A. M. Campos, R. Landers and S. A. S. Machado, Analyst, 2014, 139, 4634-4640.

144 D. Sangamithirai, S. Munusamy, V. Narayanan and A. Stephen, Mater. Sci. Eng., C, 2018, 91, 512-523.

145 B. Si and E. Song, Microelectron. Eng., 2018, 187-188, 58-65. 146 C. J. Kimble, D. M. Johnson, B. A. Winter, S. V. Whitlock, K. R. Kressin, A. E. Horne, J. C. Robinson, J. M. Bledsoe, S. J. Tye, S.-Y. Chang, F. Agnesi, C. J. Griessenauer, D. Covey, Y.-M. Shon, K. E. Bennet, P. A. Garris and K. H. Lee, Conference proceedings Annual International Conference of the IEEE Engineering in Medicine and Biology Society, Annual Conference, 2009 IEEE Engineering in Medicine and Biology Society, 2009, pp. 4856-4859.

147 K. H. Lee, S.-Y. Chang, D.-P. Jang, I. Kim, S. Goerss, J. Van Gompel, P. Min, K. Arora, M. Marsh, S. C. Hwang, C. J. Kimble, P. Garris, C. Blaha and K. E. Bennet, 
Conference proceedings Annual International Conference of the IEEE Engineering in Medicine and Biology Society, Annual Conference, 2009 IEEE Engineering in Medicine and Biology Society, 2011, pp. 677-680.

148 K. H. Lee, J. L. Lujan, J. K. Trevathan, E. K. Ross, J. J. Bartoletta, H. O. Park, S. B. Paek, E. N. Nicolai, J. H. Lee, H.-K. Min, C. J. Kimble, C. D. Blaha and K. E. Bennet, Sci. Rep., 2017, 7, 46675.

149 K. L. Parent, D. F. Hill, L. M. Crown, J.-P. Wiegand, K. F. Gies, M. A. Miller, C. W. Atcherley, M. L. Heien and S. L. Cowen, Anal. Chem., 2017, 89, 2790-2799.

150 E. Castagnola, N. W. Vahidi, S. Nimbalkar, S. Rudraraju, M. Thielk, E. Zucchini, C. Cea, S. Carli, T. Q. Gentner, D. Ricci, L. Fadiga and S. Kassegne, MRS Adv., 2018, 3, 1629-1634.

151 C. N. Hobbs, J. A. Johnson, M. D. Verber and R. M. Wightman, Analyst, 2017, 142, 2912-2920.

152 J. Dragas, V. Viswam, A. Shadmani, Y. Chen, R. Bounik, A. Stettler, M. Radivojevic, S. Geissler, M. E. J. Obien and J. Müller, IEEE J. Solid-State Circuits, 2017, 52, 1576-1590.

153 L. F. Mohammad-Zadeh, L. Moses and S. M. GwaltneyBrant, J. Vet. Pharmacol. Ther., 2008, 31, 187-199.

154 M. Berger, J. A. Gray and B. L. Roth, Annu. Rev. Med., 2009, 60, 355-366.

155 K. N. Huggins, T. A. Mathews, J. L. Locke, K. T. Szeliga, D. P. Friedman, A. J. Bennett and S. R. Jones, Alcohol, 2012, 46, 371-376.

156 C. E. John and S. R. Jones, in Electrochemical Methods for Neuroscience, CRC Press/Taylor \& Francis, 2007.

157 B. P. Jackson, S. M. Dietz and R. M. Wightman, Anal. Chem., 1995, 67, 1115-1120.

158 J. A. Stamford, Z. L. Kruk, J. Millar and R. M. Wightman, Neurosci. Lett., 1984, 51, 133-138.

159 O. Gonzalez, J. T. Berry, L. R. Mcknight-Eily, T. Strine, K. W. Edwards and J. B. Croft, Current Depression Among Adults - United States, 2006 and 2008, Center for Disease Control and Prevention, Hyattsville, MD, 2010.

160 K. M. Wood, A. Zeqja, H. F. Nijhout, M. C. Reed, J. Best and P. Hashemi, J. Neurochem., 2014, 130, 351-359.

161 A. West, J. Best, A. Abdalla, F. Nijhout, M. Reed and P. Hashemi, Neurochem. Int., 2018, 123, 50-58.

162 A. Abdalla, C. W. Atcherley, P. Pathirathna, S. Samaranayake, B. Qiang, E. Peña, S. L. Morgan, M. L. Heien and P. Hashemi, Anal. Chem., 2017, 89, 97039711.

163 I. M. Anderson and B. M. Tomenson, J. Psychopharmacol., 1994, 8, 238-249.

164 K. M. Wood and P. Hashemi, ACS Chem. Neurosci., 2013, 4, 715-720.

165 E. C. Dankoski, S. Carroll and R. M. Wightman, J. Neurochem., 2016, 136, 1131-1141.

166 D. Sames, M. Dunn, R. J. Karpowicz Jr and D. Sulzer, ACS Chem. Neurosci., 2013, 4, 648-651.
167 R. E. Brown, D. R. Stevens and H. L. Haas, Prog. Neurobiol., 2001, 63, 637-672.

168 H. L. Haas, O. A. Sergeeva and O. Selbach, Physiol. Rev., 2008, 88, 1183-1241.

169 K. Pihel, S. Hsieh, J. W. Jorgenson and R. M. Wightman, Anal. Chem., 1995, 67, 4514-4521.

170 S. Threlfell, S. J. Cragg, I. Kalló, G. F. Turi, C. W. Coen and S. A. Greenfield, J. Neurosci., 2004, 24, 8704-8710.

171 S. Threlfell, R. Exley, S. J. Cragg and S. A. Greenfield, J. Neurochem., 2008, 107, 745-755.

172 S. Samaranayake, A. Abdalla, R. Robke, H. F. Nijhout, M. C. Reed, J. Best and P. Hashemi, J. Neurochem., 2016, 138, 374-383.

173 R. J. Moran, K. T. Kishida, T. Lohrenz, I. Saez, A. W. Laxton, M. R. Witcher, S. B. Tatter, T. L. Ellis, P. E. M. Phillips and P. Dayan, Neuropsychopharmacology, 2018, 43, 1425.

174 H. Xu, L. Wang, J. Luo, Y. Song, J. Liu, S. Zhang and X. Cai, Sensors, 2015, 15, 1008-1021.

175 M. Z. H. Khan, X. Liu, Y. Tang, J. Zhu, W. Hu and X. Liu, Microchim. Acta, 2018, 185, 439.

176 R. Robke, P. Hashemi and E. Ramsson, HardwareX, 2018, e00051, DOI: 10.1016/j.ohx.2018.e00051.

177 H. L. Rowley, K. F. Martin and C. A. Marsden, Neuroscience, 1995, 68, 415-422.

178 N. J. Reinhoud, H.-J. Brouwer, L. M. van Heerwaarden and G. A. H. Korte-Bouws, ACS Chem. Neurosci., 2013, 4, 888894.

179 N. T. Iwai, M. Kramaric, D. Crabbe, Y. Wei, R. Chen and M. Shen, Anal. Chem., 2018, 90, 3067-3072.

180 I. Hossain, C. Tan, P. T. Doughty, G. Dutta, T. A. Murray, S. Siddiqui, L. Iasemidis and P. U. Arumugam, Front. Neurosci., 2018, 12, 500.

181 A. C. Schmidt, L. E. Dunaway, J. G. Roberts, G. S. McCarty and L. A. Sombers, Anal. Chem., 2014, 86, 7806-7812.

182 P. Pyakurel, E. Privman Champaloux and B. J. Venton, ACS Chem. Neurosci., 2016, 7, 1112-1119.

183 M. D. Nguyen and B. J. Venton, Comput. Struct. Biotechnol. J., 2015, 13, 47-54.

184 M. D. Nguyen, A. E. Ross, M. Ryals, S. T. Lee and B. J. Venton, Pharmacol. Res. Perspect., 2015, 3, e00189.

185 S. Balfanz, T. Strünker, S. Frings and A. Baumann, J. Neurochem., 2005, 94, 1168.

186 M. Ganesana and B. J. Venton, PLoS One, 2018, 13, e0196932.

187 K. E. Bennet, J. R. Tomshine, H.-K. Min, F. S. Manciu, M. P. Marsh, S. B. Paek, M. L. Settell, E. N. Nicolai, C. D. Blaha, A. Z. Kouzani, S.-Y. Chang and K. H. Lee, Front. Hum. Neurosci., 2016, 10, 102.

188 L. Naji, A. Carrillo-Vico, J. M. Guerrero and J. R. Calvo, Life Sci., 2004, 74, 2227-2236.

189 R. J. Reiter, Experientia, 1993, 49, 654-664.

190 A. L. Hensley, A. R. Colley and A. E. Ross, Anal. Chem., 2018, 90, 8642-8650.

191 M. T. Cryan and A. E. Ross, Analyst, 2019, 144, 249-257. 